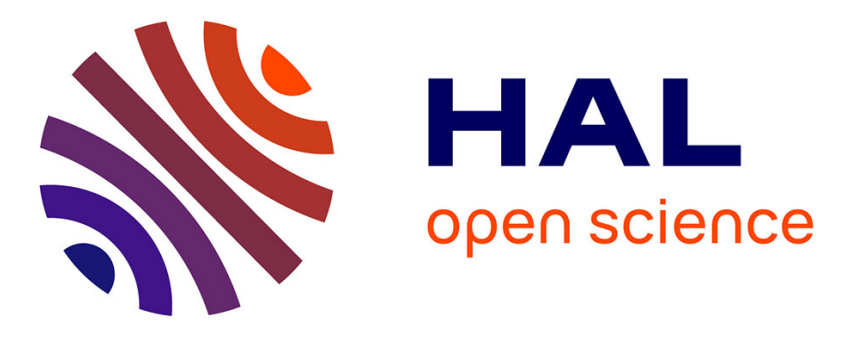

\title{
A pressure solution creep law for quartz from indentation experiments
}

Jean Pierre Gratier, Robert Guiguet, Francois Renard, Liliane Jenatton, Dominique Bernard

\section{- To cite this version:}

Jean Pierre Gratier, Robert Guiguet, Francois Renard, Liliane Jenatton, Dominique Bernard. A pressure solution creep law for quartz from indentation experiments. Journal of Geophysical Research : Solid Earth, 2009, 114, pp.B03403. 10.1029/2008JB005652 . insu-00352937

\section{HAL Id: insu-00352937 https://hal-insu.archives-ouvertes.fr/insu-00352937}

Submitted on 11 Mar 2021

HAL is a multi-disciplinary open access archive for the deposit and dissemination of scientific research documents, whether they are published or not. The documents may come from teaching and research institutions in France or abroad, or from public or private research centers.
L'archive ouverte pluridisciplinaire HAL, est destinée au dépôt et à la diffusion de documents scientifiques de niveau recherche, publiés ou non, émanant des établissements d'enseignement et de recherche français ou étrangers, des laboratoires publics ou privés. 


\title{
A pressure solution creep law for quartz from indentation experiments
}

\author{
Jean-Pierre Gratier, ${ }^{1}$ Robert Guiguet, ${ }^{1}$ François Renard, ${ }^{2,3}$ Liliane Jenatton, ${ }^{1}$ \\ and Dominique Bernard ${ }^{4}$ \\ Received 26 February 2008; revised 31 July 2008; accepted 12 November 2008; published 6 March 2009.
}

[1] Indenter experiments have been performed on quartz crystals in order to establish a pressure solution creep law relevant at upper to middle crustal conditions. This deformation mechanism contributes to Earth's crust geodynamics, controlling processes as different as fault permeability, strength, and stress evolution during interseismic periods or mechanochemical differentiation during diagenesis and metamorphism. Indenter experiments have been performed at $350^{\circ} \mathrm{C}$ and $20-120 \mathrm{MPa}$ during months with differential stress varying from 25 to $350 \mathrm{MPa}$. Several experimental parameters were varied: nature of quartz (synthetic or natural), nature of fluid, manner in which the solid/ solution/solid interface was filled, and orientation of the indented surfaces versus quartz crystallographic c axis. Significant strain rates could only be obtained when using high-solubility solutions $\left(\mathrm{NaOH} 1 \mathrm{~mol} \mathrm{~L}^{-1}\right)$. Displacement rates of the indenter were found activated by differential stress, with exponential dependence, as theoretically predicted. The mean thickness of the trapped fluid phase below the indenter was estimated in the range 2-10 $\mathrm{nm}$. Moreover, the development of this trapped fluid phase was relatively fast and allowed fluid penetration into previously dry contact regions by marginal dissolution. The indenter displacement rate was driven by differential stress, and its kinetics was controlled by diffusion along the trapped fluid and the development of a morphological roughness along the interface. Conversely, marginal strain energy driven dissolution was observed around the indenter, and its kinetics was controlled by freesurface reaction. These experimental results are applied to model the interactions between pressure solution and brittle processes in fault zones, providing characteristic time scales for postseismic transitory creep and sealing processes in quartz-rich rocks.

Citation: Gratier, J.-P., R. Guiguet, F. Renard, L. Jenatton, and D. Bernard (2009), A pressure solution creep law for quartz from indentation experiments, J. Geophys. Res., 114, B03403, doi:10.1029/2008JB005652.

\section{Introduction}

[2] Pressure solution creep is a major mechanism of rock deformation in the upper crust, competing with cataclasis. Both mechanisms are well documented in exhumed natural fault rocks deformed within the upper crust. These mechanisms tend to become subordinate to thermally activated creep at depths greater than $10-15 \mathrm{~km}$ [Guéguen and Palciauskas, 1994; Poirier, 1985]. Cataclasis can be very fast, with strain rates as high as $10^{-2}$ to $10^{0} \mathrm{~s}^{-1}$, often associated with seismic processes. It is the most common mechanism of deformation that can be reproduced in

\footnotetext{
${ }^{1}$ Laboratoire de Géophysique Interne et Tectonophysique, Observatoire de Grenoble, University Joseph Fourier, CNRS, Grenoble, France.

${ }^{2}$ Laboratoire de Géodynamique des Chaînes Alpines, Observatoire de Grenoble, University Joseph Fourier, CNRS, Grenoble, France.

${ }^{3}$ Also at Physics of Geological Processes, University of Oslo, Oslo, Norway.

${ }^{4}$ Institut de Chimie de la matière condensée de Bordeaux, University of Bordeaux, CNRS, Pessac, France.

Copyright 2009 by the American Geophysical Union. 0148-0227/09/2008JB005652\$09.00
}

laboratory-scale experiments under upper crust pressure and temperature conditions [Paterson and Wong, 2005]. However, cataclasis requires high differential stresses and is not representative of the ductile deformation that takes place in the upper crust as slow creeping processes [Ramsay and Huber, 1987] with very low differential stresses [Cox and Etheridge, 1989; Gratier and Gamond, 1990]. In contrast, pressure solution creep and all other ductile deformation processes accommodated by mass transfer in a solution [Wintsch et al., 1995] do not require high differential stresses [Rutter, 1976]. However, as chemical reactions in a nonhydrostatic stress field are generally very slow, resulting in strain rates commonly found in natural deformation and ranging from $10^{-11}$ to $10^{-15} \mathrm{~s}^{-1}$ [Pfiffner and Ramsay, 1982] reproducing such low strain rates in the presence of a fluid in the laboratory is a real challenge [Paterson, 2001].

[3] Nevertheless, experiments are the only way to evaluate the kinetics of such processes. Strain rates as low as $10^{-11} \mathrm{~s}^{-1}$ may be measured in laboratory experiments [Bérest et al., 2004; Dysthe et al., 2003; Le Guen et al., 2007], however this can only be done for pressure solution by activating the kinetics of the processes, for example, by 
using a mineral with high solubility in water such as halite [Hickman and Evans, 1991; Tada and Siever, 1986; Urai et al., 1986] or by increasing the solubility of the solution, for example, using $\mathrm{NaOH}$ solutions for quartz [Gratier and Guiguet, 1986]. The kinetics may also be activated by working at very high temperatures [Giger et al., 2007; Tenthorey and Cox, 2006]. Another constrain is that pressure solution creep laws, like other mass transfer creep laws, are very sensitive to the geometry of mass transfer [Poirier, 1985].

[4] To solve this problem, indenter experiments represent a well adapted technique since it allows maintaining a constant geometry, and, consequently, a constant distance of mass transfer, all along the duration of deformation [Gratier, 1993; Hickman and Evans, 1991; Tada and Siever, 1986]. The principle of the indenter technique experiment is to measure the displacement rate of an indenter that pressure dissolves a crystal, in order to establish creep and compaction laws. In the present study, a steel indenter was loaded over a crystal surface. Stress-enhanced dissolution occurred below the indenter, mimicking the process of grain-grain contact stress-controlled dissolution observed in many natural systems (e. g. sedimentary basins, fault gouges). The displacement of the indenter was measured with time, providing a creep rate law. Such experiments allow determination of (1) the driving forces predicted by theoretical approaches: normal stress work energy versus elastic-plastic strain energy [Lehner, 1995; Leroy and Heidug, 1994; Robin, 1978; Shimizu, 1995], (2) the limiting processes: diffusion versus reaction limited [Gratier and Guiguet, 1986; Hickman and Evans, 1991; Rutter, 1976; Zubtsov et al., 2004], and more precisely the conditions of the shifting from one to another driving forces or from one to another limiting processes, and (3) information on deformation mechanisms partitioning [Karcz et al., 2006; Tada and Siever, 1986].

[5] In the present study, we have performed indenter experiments on quartz single crystals, under thermodynamic conditions relevant for upper to middle crust processes. Because of the slow kinetics of pressure solution creep on quartz, this study represents an experimental effort over a 10 year period. A pressure solution law could be derived from the measured displacement rate by varying stress, fluid composition, and type of quartz (natural or synthetic). We also present some applications to the modeling of pressure solution creep-fracturing interactions that lead to transitory creep and sealing processes during the seismic cycle in active faults.

\section{Basics of Pressure Solution Creep}

\subsection{Thermodynamics: The Driving Forces}

[6] In order to settle the basic principles of pressure solution creep, one may consider what happens when letting a loaded indenter in contact with a solid surface that was previously in equilibrium with its saturated solution at a fluid pressure $P_{f}$ (Figure 1a). Stress under the indenter increases the chemical potential of the solid compared to the solid free surface at zero stress far away from the indenter [Gibbs, 1877]. Though Gibbs free energy is not defined for a nonhydrostatically stressed solid, dissolution and precipitation of a solid is commonly described as an approximate relationship [see Lehner, 1990, 1995] by the surface chemical potential:

$$
\Delta \mu=\Delta f+V_{s} \Delta \sigma_{n}+\Delta E_{s}
$$

where $\Delta \mu$ is the difference in chemical potential of the dissolved component between the maximum stressed part (under the indenter) and the free solid/fluid surface away from the indenter, $\Delta \sigma_{n}$ is the difference between the normal stress component under the indenter and the fluid pressure $P_{f}$ on the solid away from the indenter, and is simply named $\sigma_{n}$ in the creep relations, $V_{s}$ is the molar volume of the solid. $E_{s}$ is the curvature-related potential: $E_{s}=\gamma V_{s}(1 / r+1 / R)$, where $\gamma$ is the interfacial energy, $r$ and $R$ are the principal radii of curvature [Kingery et al., 1976]. The molar Helmholtz free energy, $\Delta f$, gathers various contributions [Paterson, 1973]: $\Delta f=\Delta E_{e}+\Delta E_{p}$, where $E_{e}$ is the elastic strain energy and $E_{p}$ is the plastic strain energy due to dislocations that are induced by the indenter. Both terms vanish along the free surface away from the indenter. Equation (1) characterizes the chemical potential of the solid at each point on the solid/fluid surface. This potential varies from the contact surface with a normal stress $\sigma_{n}$ to the free face of the solid, away from the indenter, at pressure $P_{f}$. The driving force for material transfer along the solid/fluid interface is therefore the difference in chemical potential between the stressed interface and the free surface. The spatial distributions of the stress components and strain energy below and around the indenter are given in Figure 1c (L. Angheluta, personal communication, 2008). The effect of the difference in normal stress $\left(\Delta \sigma_{n}\right)$ is approximately 1000 times greater than that of other effects, specifically, the elastic strain energy as calculated in Figure 1c. The normal stress effect alone must lead to a hole with the same diameter as the indenter (Figure 1b). However, outside the indenter contact, but in the vicinity of its boundary, $\Delta f$ is increased by the strain energy and dissolution can also occur there [Tada and Siever, 1986]. Consequently, there is a progressive decrease of the chemical potential away from the boundary of the indenter (Figure 1c). This effect may lead to a hole with a diameter larger than the indenter (Figure 1b).

\subsection{Kinetics: The Limiting Processes}

[7] Pressure solution is a sequence of three successive processes: dissolution, mass transfer and reprecipitation (Figure 1a). If one of these processes is much slower than the others, it imposes its kinetics on the whole deformation process and is termed the rate limiting process [Rutter, 1976]. Various creep equations may be written according to which process is rate limiting, an approach, which is summarized briefly below. However, when the kinetics of the three processes are very similar, the driving force is partitioned subequally between these processes, leading to a relatively complex relationship [Raj, 1982].

[8] In this introduction on pressure solution basic concepts, we only present the simplest relationships when the driving force for pressure solution is the difference in normal 


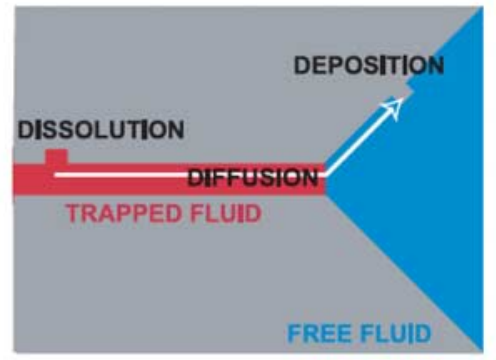

(a)

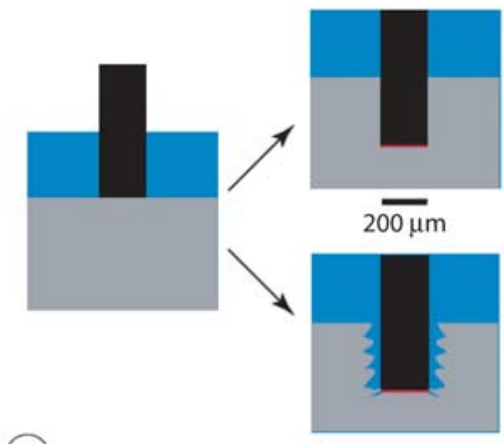

(b)

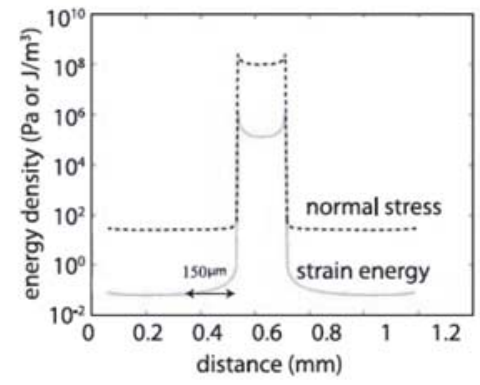

(c)
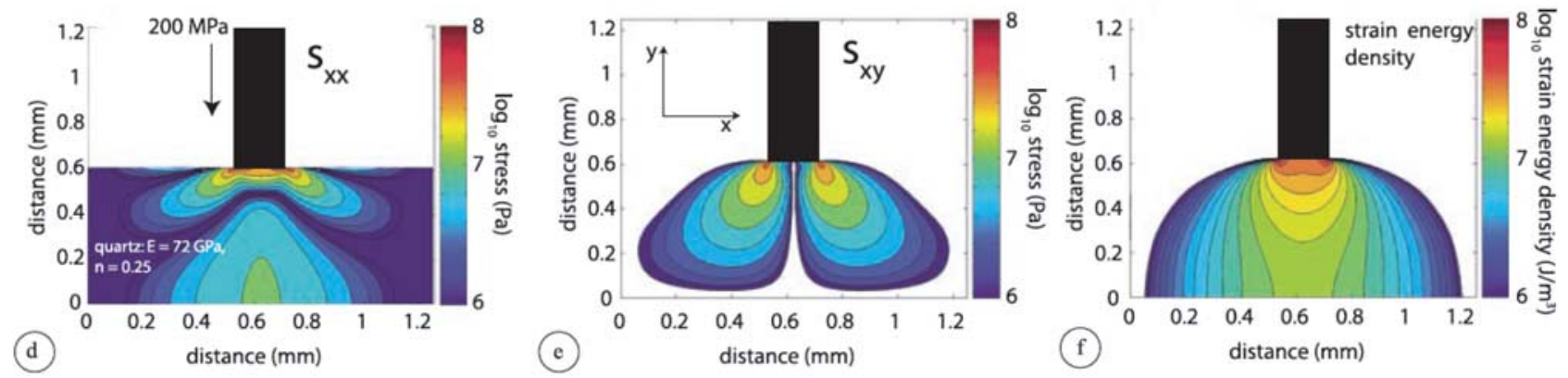

Figure 1. Basics concepts of pressure solution creep using an indenter technique. (a) Deformation by dissolution along a contact occurs by three successive processes: dissolution is enhanced in the region of maximum compressive stress (below the indenter), then matter diffuses along a trapped fluid phase (red) to the zone of minimum stress (equal to free face with fluid pressure) where deposition occurs. (b) Various driving forces revealed by the shape of indented holes: effect of the difference in normal stresses between the indenter contact and the surrounding free fluid shown by a dissolution hole of the same diameter as the indenter (top) and coupled effect of the difference in normal stresses and the difference in elastic strain energy around the indenter, shown by a hole with a diameter larger than the indenter. (c) Comparison of the evolution of normal stress and strain energy values along the fluid-solid interface, below and away from an indenter. (d) Distribution of the horizontal stress below the indenter. (f) Distribution of the shear stress below the indenter (same conditions as in Figure 1d). (e) Distribution of strain energy density below the indenter (same conditions as Figure 1d). The stress components in 2-D have been calculated with a finite element method and using the elastic parameters (Young's modulus $E=72 \mathrm{GPa}$ and Poisson's ratio $\nu=0.25$ ) of the quartz crystal and the steel indenter (calculation courtesy of L. Angheluta).

stress between contacting and free surfaces. When analyzing indenter experiments, the displacement rate $\Delta x / \Delta t$ is used instead of the strain rate $\Delta d / d \Delta t$. Creep laws may be derived from these relationships (see section 6) when the characteristic length of the closed system is assumed to be equal to the indenter diameter $(d) . \Delta x / \Delta t$ is calculated by measuring the depth of the hole after the experiment $(\Delta x)$ and the duration of the experiment $(\Delta t)$. We thus consider an average displacement rate with time, assuming a steady state dissolution process.

Model R

$$
\Delta x / \Delta t=\alpha \mathrm{kV}_{\mathrm{s}}^{2} \sigma_{\mathrm{n}}^{n} / \mathrm{RT}
$$

or

$$
\Delta x / \Delta t=\alpha^{\prime} k V_{s}\left(e^{\sigma_{n} V_{s} / R T}-1\right)
$$

is relevant if either dissolution or precipitation kinetics is the rate-limiting processes [Raj, 1982; Spiers et al., 2004].

Model D

$$
\Delta x / \Delta t=\beta D w c V_{s}^{2} \sigma_{n}^{n} / R T d^{2}
$$

or

$$
\Delta x / \Delta t=\beta^{\prime} \operatorname{DwcV}_{\mathrm{s}}\left(\mathrm{e}^{3 \sigma_{n} \mathrm{~V}_{\mathrm{s}} / \mathrm{RT}}-1\right) / \mathrm{d}^{2}
$$

applies when diffusion flux through a fluid phase under stress below the indenter is the rate-limiting process [Rutter, 1976; Dewers and Ortoleva, 1990].

[9] In equations (2) to (4), $\alpha, \alpha^{\prime}, \beta, \beta^{\prime}$ are dimensionless constants that depend on the geometry of the interface, $d$ is the indenter diameter $(\mathrm{m}), t$ is time $(\mathrm{s}), k$ is the kinetics constant for dissolution or precipitation reaction $\left(\mathrm{mol} \mathrm{m}^{-2}\right.$ $\left.\mathrm{s}^{-1}\right), c$ is the solubility of the diffusing solid $\left(\mathrm{mol} \mathrm{m} \mathrm{m}^{-3}\right), V_{s}$ 
is the molar volume of the stressed solid $\left(\mathrm{m}^{3} \mathrm{~mol}^{-1}\right), R$ is the gas constant $\left(8.32 \mathrm{~m}^{3} \mathrm{~Pa} \mathrm{~mol}^{-1} \mathrm{~K}^{-1}\right), T$ is the temperature $(\mathrm{K}), D$ is the diffusion constant along the stressed interface $\left(\mathrm{m}^{2} \mathrm{~s}^{-1}\right)$, and $w$ is the thickness of the fluid interface $(\mathrm{m})$ along which diffusion occurs. The factor 3 in the exponential of equation (5) [Dewers and Ortoleva, 1990] reflects the fact that for balance of forces during a constant approach of two planar surfaces, the normal stress at the center of the contact between the surfaces is higher than the average stress across the contact [Weyl, 1959; Rutter, 1976].

[10] Several authors have discussed the structure of the fluid phase trapped under the indenter. Three principal models can describe such a stressed fluid phase: (1) the thin-fluid film model with continuous trapped fluid phase [Rutter, 1976; Weyl, 1959], (2) the island-channel model, with solid/solid bridges and channels [Raj, 1982; Spiers and Schutjens, 1995], and (3) the microcracking grain boundary model, with channels developing at sites of grain boundary cracks [den Brok, 1998; Gratz, 1991]. In the above theoretical relations, we consider a simple thin fluid model with a mean diffusion coefficient, $D$, and a mean thickness of the fluid phase $w$. Using the indenter experiments data, one can estimate a mean value of the product $D w$.

[11] The stress exponent, $n$, is equal to 1 in most pressure solution creep laws. However, for several reasons this is only true to a first approximation:

[12] 1. When dissolution or precipitation is rate controlling (equation (2)), $n$ varies according to the magnitude of the interface velocity versus the driving force relation: $n=2$ for spiral growth/dissolution (2-D nucleation or dissolution on surfaces that are smooth and flat at the atomic scale) and $n=1$ for a rough interface (evolution without a layer-tolayer mechanism of growth or dissolution) [Niemeijer and Spiers, 2002].

[13] 2. When diffusion is rate controlling and maintains the balance of the diffusive flux out of the fluid film (equation (4)) such that the contact remains flat, the normal stress at the center of the contact must be higher than the average stress across the contact [Weyl, 1959]. In this situation, a linear strain rate versus stress relation is only predicted at stress values of $\Delta \sigma_{n}$ less than $30 \mathrm{MPa}$ [Rutter, 1976]. As the difference in solubility of the solid between the zone of dissolution and the zone of deposition depends exponentially on the chemical potential, a general relation have been derived by Dewers and Ortoleva [1990] (equation (5)).

\subsection{Indenter Experiments: Relevant Parameters}

[14] We now propose to test these models using indenter experiments. Evaluating the validity of pressure solution creep laws under experimental conditions is not easy. The expected fastest strain rates are of the order of $10^{-11} \mathrm{~s}^{-1}$ [Rutter, 1976], at the detection limit of what can be achieved experimentally. To achieve rates measurable under laboratory conditions, the kinetics of pressure solution creep should be artificially enhanced:

[15] 1. The solubility of the solid in solution can be increased either by using salts [Bérest et al., 2004; Dysthe et al., 2003; Le Guen et al., 2007] or by using highsolubility solutions [Gratier and Guiguet, 1986], with the disadvantage of inducing potential chemical side effects: even modest concentrations of foreign ions such as alkali cations, or $\mathrm{pH}$ variations, can strongly increase the kinetics reaction rate coefficients $(k)$, often by several orders of magnitude. Both diffusion and reaction controlled pressure solution process can be accelerated by adding $\mathrm{NaOH}$.

[16] 2. The temperature can be increased [Cox and Paterson, 1991] but only at the risk of favoring solid-state creep mechanisms with a higher activation energy than that of pressure solution (e.g., Nabarro-Herring creep, a mechanism which is otherwise unlikely to operate in the upper crust [Rutter, 1983]).

[17] 3. Stress can be increased at the risk of inducing either intracrystalline plasticity (dislocation glide plus climb) or cataclasis.

[18] 4. The diameter of the indenter must be as small as possible if diffusion is rate limiting.

[19] These constraints prevented us from exploring the effect of all the parameters included in the various pressure solution creep laws. For example, the limiting process could vary with thermodynamic conditions, i.e., pressure solution of quartz is thought to be controlled by reaction rate at low temperature and by diffusion rate at high temperature [Oelkers et al., 1996; Renard et al., 1997]. It was not possible to explore a wide range of temperature that could separate dissolution controlled process (with high activation energy: 70-90 kJ mol${ }^{-1}$ ) [Gratier and Jenatton, 1984], from diffusion controlled process (with low activation energy: $10-15 \mathrm{~kJ} \mathrm{~mol}^{-1}$ ) [Rutter, 1976]. It was also not possible to explore the effect of the relationship between displacement rate, and the diameter of the indenter (from no effect for the model $\mathrm{R}$ law to $1 / d^{2}$ dependence for the model D law) since only the smallest diameter $(200 \mu \mathrm{m})$ gave significant results. However, we used the reaction rate difference of the various crystallographic face of quartz to identify the limiting process. The nature of solids and fluids is also a key factor as, for example, the effect of pore fluid impurity ions that slow the reaction rate [Zhang et al., 2002] and consequently favor reaction control on mass transfer rates in some natural systems. We partly explored such effect by varying the $\mathrm{pH}$ of the solution.

\section{Experimental Setup}

[20] A schematic view of the experimental device is given in Figure 2. A needle-like stainless steel cylindrical indenter with a small diameter (here $200 \mu \mathrm{m}$ for most runs) is mounted under a free-moving piston. This indenter is put in contact with a quartz crystal in presence of its saturated solution. A dead weight fixed on the piston sets the stress. The device is maintained within a pressure vessel during several weeks or months at constant temperature and fluid pressure. The depth of the dissolution hole is measured at the end of the experiment and divided by the duration of the experiment to obtain the indentation rate. Several experimental parameters were varied (see Table 1).

[21] 1. The type of quartz was either synthetic or natural mineral. For synthetic quartz, samples were taken from crystals grown in $\mathrm{NaOH} 1 \mathrm{M}$ solution by the Société Industrielle des Combustibles Nucléaires (Annecy, France) [Regreny, 1973]. For natural quartz, we used a homogeneous set of euhedral crystals of Arkansas. The size of all samples was the same: a cylinder of $1 \mathrm{~cm}$ of diameter and 


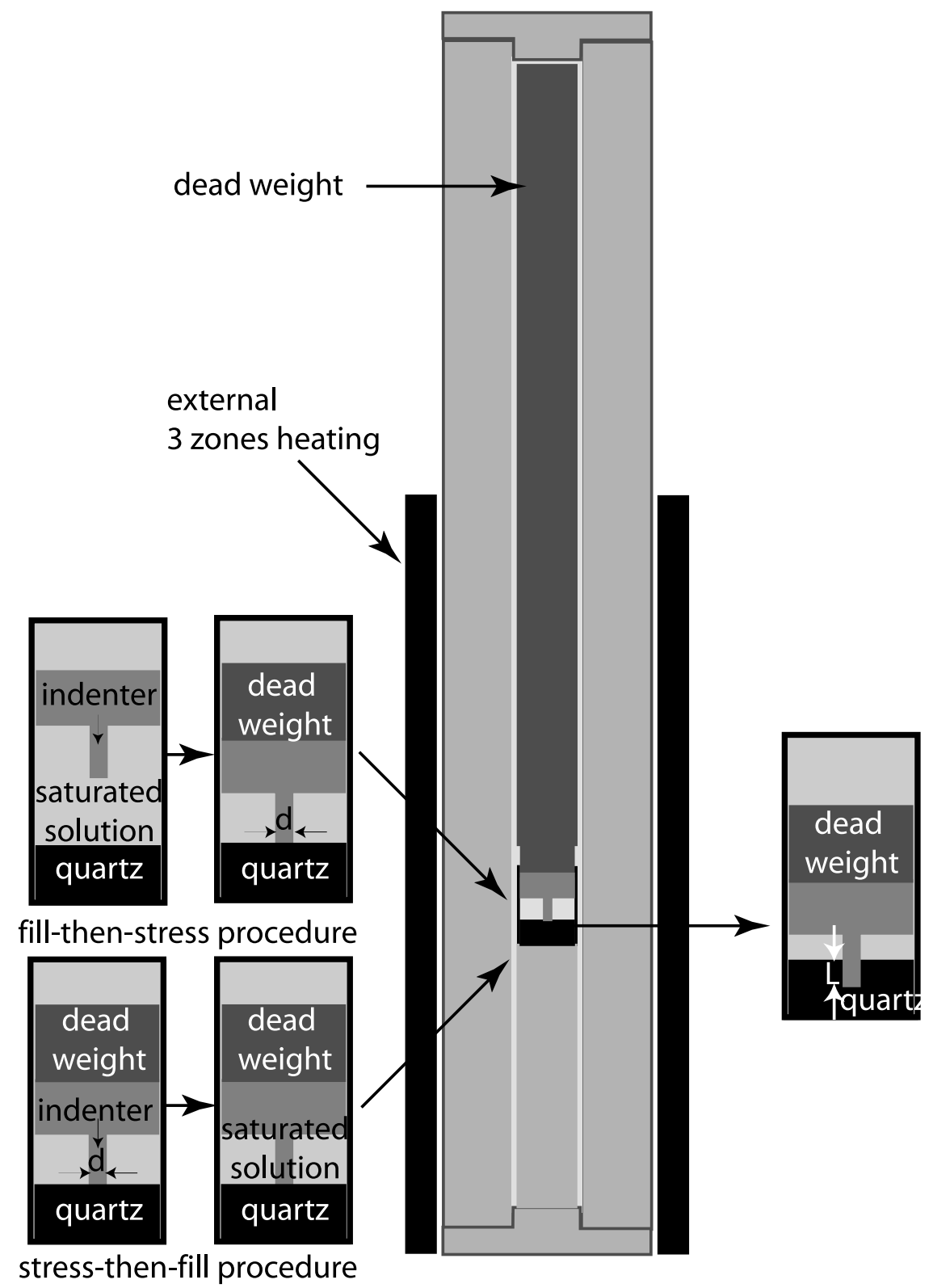

Figure 2. Principle of the indenter technique experiments: A dead weight let on the piston sets the differential stress (difference between axial stress and free fluid pressure, ranging from 27 to $348 \mathrm{MPa}$ ). The device is maintained within a pressure vessel during several weeks or months at constant temperature $\left(350\right.$ or $360^{\circ} \mathrm{C}$ ) and fluid pressure (20 to $120 \mathrm{MPa}$ ). The depth of the dissolution holes is measured at the end of the experiment. The way the interface solid/solution/solid is filled is varied (Figure 2, left) with either pouring the solution before setting the stress (the fill-then-stress procedure, Figure 2, top left) or loading the indenter before pouring the solution (stress-then-fill procedure, Figure 2, bottom left).

$0.5 \mathrm{~cm}$ height was cored in a quartz crystal, either parallel or perpendicular to its crystallographic c axis.

[22] 2. The nature of the solution was either $\mathrm{NaOH} 1 \mathrm{~mol}$ $\mathrm{L}^{-1}$ or dionized water. Experiments were also run without any fluid (experiments referred as dry). The choice of $\mathrm{NaOH} 1 \mathrm{M}$ solution is linked to the experimental procedure used to grow synthetic quartz. It was shown by Laudise [1970] and Regreny [1973] that such solution is the best solvent to increase both quartz solubility and the kinetics of hydrothermal quartz synthesis.
[23] 3. The temperature was either $360^{\circ} \mathrm{C}$ (for synthetic quartz) or $350^{\circ} \mathrm{C}$ (for natural quartz). A homogeneous temperature through the whole sample was obtained by using three independent heating elements at three levels within the pressure vessel. Consequently, the temperature was well regulated and did not vary by more than one degree. However, because of the long duration of the experiments that most often last for several weeks up to seven months, it happened that temporary electric power supply breakdown led to some periods of lower temperature 
Table 1. Data Set of the Indenter Experiments ${ }^{\mathrm{a}}$

\begin{tabular}{|c|c|c|c|c|c|c|}
\hline Sample & Fluid Solution & Indented Face $^{\mathrm{a}}$ & Way of Filling ${ }^{\mathrm{b}}$ & Stress $^{\mathrm{c}}(\mathrm{MPa})$ & Duration (days) & Hole Depth $^{\mathrm{d}}(\mu \mathrm{m})$ \\
\hline NQ1-1 & $\mathrm{NaOH} \mathrm{M}$ & $\mathrm{m}$ prismatic face & stress->-fill & 170.4 & 60 & 45 \\
\hline NQ1-2 & $\mathrm{NaOH} \mathrm{M}$ & $\mathrm{m}$ prismatic face & stress- $>$-fill & 80.7 & 60 & 12 \\
\hline NQ2-1-1 & $\mathrm{NaOH} \mathrm{M}$ & $\mathrm{m}$ prismatic face & stress->-fill & 56.7 & 60 & 10 \\
\hline NQ2-1-2 & $\mathrm{NaOH} \mathrm{M}$ & $\mathrm{m}$ prismatic face & stress->-fill & 56.7 & 60 & 10 \\
\hline NQ2-1-3 & $\mathrm{NaOH} \mathrm{M}$ & $\mathrm{m}$ prismatic face & stress->-fill & 56.7 & 60 & 10 \\
\hline NQ2-1-4 & $\mathrm{NaOH} \mathrm{M}$ & $\mathrm{m}$ prismatic face & stress->-fill & 170.3 & 60 & 25 \\
\hline NQ2-3-1 & $\mathrm{NaOH} \mathrm{M}$ & $\mathrm{m}$ prismatic face & stress->-fill & 26.9 & 60 & 4 \\
\hline NQ2-3-2 & $\mathrm{NaOH} \mathrm{M}$ & $\mathrm{m}$ prismatic face & stress->-fill & 26.9 & 60 & 5 \\
\hline NQ2-3-3 & $\mathrm{NaOH} \mathrm{M}$ & m prismatic face & stress->-fill & 26.9 & 60 & 6 \\
\hline NQ2-3-6 & $\mathrm{NaOH} \mathrm{M}$ & $\mathrm{m}$ prismatic face & stress->-fill & 80.5 & 60 & 20 \\
\hline NQ4-2 & $\mathrm{NaOH} \mathrm{M}$ & $\mathrm{m}$ prismatic face & stress- $>$-fill & 348.3 & 60 & 150 \\
\hline NQ5-2 & $\mathrm{NaOH} \mathrm{M}$ & $\mathrm{m}$ prismatic face & stress->-fill & 173.4 & 60 & 125 \\
\hline NQ6-1 & $\mathrm{NaOH} \mathrm{M}$ & $\mathrm{m}$ prismatic face & stress->-fill & 243.1 & 10 & 10 \\
\hline NQ6-2 & $\mathrm{NaOH} \mathrm{M}$ & $\mathrm{m}$ prismatic face & stress->-fill & 169.8 & 133 & 250 \\
\hline NQ6-3 & $\mathrm{NaOH} \mathrm{M}$ & $\mathrm{m}$ prismatic face & stress->-fill & 107.8 & 133 & 25 \\
\hline NQ7-2 & $\mathrm{NaOH} \mathrm{M}$ & $\mathrm{m}$ prismatic face & stress->-fill & 186 & 125 & 50 \\
\hline NQ9-2 & $\mathrm{NaOH} \mathrm{M}$ & $\mathrm{m}$ prismatic face & stress->-fill & 243.1 & 124 & 430 \\
\hline NQ10-1 & $\mathrm{NaOH} \mathrm{M}$ & m prismatic face & fill->-stress & 288.9 & 67 & 490 \\
\hline NQ11-1 & $\mathrm{NaOH} \mathrm{M}$ & $\mathrm{m}$ prismatic face & fill->-stress & 282.3 & 120 & 280 \\
\hline NQ11-2 & $\mathrm{NaOH} \mathrm{M}$ & $\mathrm{m}$ prismatic face & fill->-stress & 241.9 & 120 & 240 \\
\hline NQ11-3 & $\mathrm{NaOH} \mathrm{M}$ & $\mathrm{m}$ prismatic face & fill->-stress & 141 & 120 & 70 \\
\hline NQ12-1 & $\mathrm{NaOH} \mathrm{M}$ & $\mathrm{m}$ prismatic face & fill->-stress & 141.6 & 228 & 420 \\
\hline NQ12-2 & $\mathrm{NaOH} \mathrm{M}$ & $\mathrm{m}$ prismatic face & fill->-stress & 114.7 & 228 & 310 \\
\hline NQ12-3 & $\mathrm{NaOH} \mathrm{M}$ & $\mathrm{m}$ prismatic face & fill->-stress & 86 & 228 & 20 \\
\hline NQ13-3 & $\mathrm{NaOH} \mathrm{M}$ & m prismatic face & fill- $>$-stress & 58.47 & 258 & 85 \\
\hline NQ14-2 & $\mathrm{NaOH} \mathrm{M}$ & $\mathrm{m}$ prismatic face & fill->-stress & 176.3 & 153 & 750 \\
\hline NQ14-3 & $\mathrm{NaOH} \mathrm{M}$ & $\mathrm{m}$ prismatic face & fill->-stress & 115.8 & 153 & 30 \\
\hline NQ15-1 & $\mathrm{NaOH} \mathrm{M}$ & $\mathrm{m}$ prismatic face & fill- $>$-stress & 171.7 & 103 & 310 \\
\hline NQ15-2 & $\mathrm{NaOH} \mathrm{M}$ & $\mathrm{m}$ prismatic face & fill->-stress & 230.5 & 97 & 220 \\
\hline NQ15-3 & $\mathrm{NaOH} \mathrm{M}$ & $\mathrm{m}$ prismatic face & fill->-stress & 199.5 & 103 & 820 \\
\hline NQ15-4 & $\mathrm{NaOH} \mathrm{M}$ & $\mathrm{m}$ prismatic face & fill->-stress & 115.8 & 97 & 30 \\
\hline NQ16-1 & $\mathrm{NaOH} \mathrm{M}$ & c basal plane & fill->-stress & 171.7 & 105 & 180 \\
\hline NQ16-4 & $\mathrm{NaOH} \mathrm{M}$ & c basal plane & fill->-stress & 115.8 & 105 & 230 \\
\hline NQ17-1 & $\mathrm{NaOH} \mathrm{M}$ & c basal plane & fill- $>$-stress & 171.1 & 160 & 870 \\
\hline NQ17-2 & $\mathrm{NaOH} \mathrm{M}$ & c basal plane & fill->-stress & 229.9 & 160 & 820 \\
\hline NQ18-1 & $\mathrm{NaOH} \mathrm{M}$ & c basal plane & fill->-stress & 171.1 & 193 & 348 \\
\hline NQ18-2 & $\mathrm{NaOH} \mathrm{M}$ & c basal plane & fill->-stress & 229.9 & 193 & 670 \\
\hline NQ18-3 & $\mathrm{NaOH} \mathrm{M}$ & c basal plane & fill->-stress & 195.5 & 193 & 900 \\
\hline NQ18-4 & $\mathrm{NaOH} \mathrm{M}$ & c basal plane & fill->-stress & 114.9 & 193 & 500 \\
\hline SQ6 & $\mathrm{NaOH} \mathrm{M}$ & $\mathrm{m}$ prismatic. face & stress- $>$-fill & 120.3 & 22 & 150 \\
\hline SQ8 & $\mathrm{NaOH} \mathrm{M}$ & m prismatic face & stress- $>$-fill & 108.6 & 10 & 50 \\
\hline SQ13 & $\mathrm{NaOH} \mathrm{M}$ & $\mathrm{m}$ prismatic face & stress->-fill & 170.5 & 32 & 103 \\
\hline SQ14 & $\mathrm{NaOH} \mathrm{M}$ & $\mathrm{m}$ prismatic face & stress->-fill & 113.8 & 32 & 66 \\
\hline SQ15 & $\mathrm{NaOH} \mathrm{M}$ & $\mathrm{m}$ prismatic face & stress->-fill & 230.5 & 32 & 165 \\
\hline SQ16 & $\mathrm{NaOH} \mathrm{M}$ & m prismatic face & stress->-fill & 200.1 & 32 & 85 \\
\hline SQ17 & $\mathrm{NaOH} \mathrm{M}$ & m prismatic face & stress->-fill & 143.9 & 32 & 30 \\
\hline SQ18 & $\mathrm{NaOH} \mathrm{M}$ & $\mathrm{m}$ prismatic face & stress->-fill & 91.7 & 32 & 45 \\
\hline SQ19 & $\mathrm{NaOH} \mathrm{M}$ & $\mathrm{m}$ prismatic face & stress->-fill & 130 & 32 & 45 \\
\hline SQ22 & $\mathrm{NaOH} \mathrm{M}$ & m prismatic face & stress->-fill & 135.8 & 32 & 30 \\
\hline NQ0-1 & Water & $\mathrm{m}$ prismatic face & fill- $>$-stress & 348 & 213 & 0 \\
\hline NQ0-2 & Water & c basal plane & fill->-stress & 348 & 213 & 0 \\
\hline NQ00-1 & Dry & c basal plane & & 348 & 180 & 0 \\
\hline NQ00-2 & Dry & $\mathrm{m}$ prismatic face & & 348 & 180 & 0 \\
\hline
\end{tabular}

a Orientation of the indented surface versus $\mathrm{C}$ axis of quartz: dissolved surfaces are either " $\mathrm{m}$ prismatic face" parallel to the c axis or "basal plane" perpendicular to the $\mathrm{c}$ axis.

${ }^{b}$ Way of filling the cell and loading the sample either the stress-then-fill (stress->-fill) or the fill-then-stress (fill->-stress) procedure.

${ }^{\mathrm{c}}$ Stress value on the indenter

${ }^{\mathrm{d}}$ Depth of the dissolution hole measured at the end of the experiment.

(sometimes down to room temperature and then up to the imposed temperature).

[24] 4. The fluid pressure was either $120 \mathrm{MPa}$ (for synthetic quartz) or $20 \mathrm{MPa}$ (for natural quartz). The fluid pressure was difficult to regulate because leakages happened sometimes during such long-duration experiments. When possible (small leak) the pressure was increased manually in order to keep the fluid pressure between 30 and 16.5 $\mathrm{MPa}$ (this last value corresponds the critical pressure of water at $350^{\circ} \mathrm{C}$ ). The fluid was always kept in thermodynamic conditions below vapor pressure, in the liquid domain. When a more drastic pressure failure occurred, the experiment was stopped and the measurement of the depth of the hole was done immediately.

[25] 5. The way the interface solid/solution/solid was filled was also varied. We used two types of procedures. In the first one, referred as "stress-then-fill," the indenter was let in contact with the sample and the dead weight was set on the indenter. Then the saturated solution previously saturated with silica powder at the temperature of the 
experiment was injected in the vessel. In this case, the solution must migrate under the indenter after the stress has been set. Fluid migration below the indenter was enhanced by roughening the indenter contact area with sand paper. In the second procedure, referred as "fill-then-stress," the crystal was immersed in the solution previously saturated with silica powder at the temperature of the experiment. Then the indenter was let in contact with the sample in order to trap a saturated fluid phase below the indenter before the stress was set. Comparing the results obtained with these two procedures gives information on how the fluid migrated through the solid/fluid/solid interface under stress.

[26] 6. Finally, the orientation of the indented surfaces versus the quartz crystallographic $\mathrm{c}$ axis was varied. The samples were cut either perpendicular or parallel to the $c$ axis. In the last case, we used either the natural $\mathrm{m}$ prismatic face or we cut the sample parallel to one of this $m$ face.

[27] After each experiment, the indenter was removed, and the hole in the quartz sample was characterized using various optical and X-ray means. Photographs were taken under optical or scanning electron microscopes. Other images were obtained using X-ray computed microtomography (beam line TOMCAT at Swiss Light Synchrotron) that gives the three-dimensional geometry of the hole and its associated structures. The roughness of areas dissolved under the indenter was also quantified using white light interferometer (WLI) micrography. This was done under a microscope (Wyko 2000 Surface Profiler from Veeco). The relative height of the sample surface at each pixel was measured with a vertical resolution of $3 \mathrm{~nm}$. The horizontal resolution depends on the choice of the lens: at the highest magnification it is $\sim 0.5 \mu \mathrm{m}$, which corresponds to the diffraction limit. The completeness of the measured data set depends on the reflectivity of the surface. For the raw samples, only $50 \%$ of the pixels can be solved by the interferometer. We have therefore gold coated several samples to increase the reflectivity of the surface. In this case, up to $99 \%$ of the pixels were resolved. The missing data were linearly interpolated with nearest neighbors.

\section{Results}

[28] A dissolution hole was never observed in dry conditions. Only indenter marks, a few micrometers deep, were obtained when using a silica saturated pure water solution and this even for very long duration experiments ( 7 months) and when using the highest stress values (Figure 3a). As in this case the depth of the hole could not be measured precisely for lower stress values, we shifted from pure water to $\mathrm{Na} \mathrm{OH} 1 \mathrm{~mol} \mathrm{~L}^{-1}$. Such basic solution increases significantly quartz solubility, a parameter that accelerates the kinetics of pressure solution creep (see equations (2), (3), (4), and (5)).

[29] Figure 3 shows some examples of the holes that formed under the indenter. One may note that cylindrical holes with a diameter equal to the indenter diameter were only obtained at low stress values (Figures 3b, 3c, and 3d). Conversely, holes larger than the indenter were obtained at high stress (Figure 3f). "En echelon" fractures were clearly associated with such a hole enlarging process (Figures 3i, $3 \mathrm{j}$, and $3 \mathrm{k}$ ). These fractures have nucleated and then propagated by dissolution during the experiments. Several fractures developed successively as the dissolution hole deepened inside the crystal. Curved solid-fluid surface at the tip of these fractures (Figures $3 \mathrm{i}$ and 31 ) demonstrate that a process of surface energy minimizing must have operated. The trapping of fluid inclusions, observed in Figure 31, is also a common marker of fracture healing processes. One can also note the development of reverse crown-shaped fractures in the crystal below the hole (Figures $3 \mathrm{~g}$ and $3 \mathrm{~h}$ ). Such fracture network that extends largely away from the hole, has the same orientation as the en echelon dissolved fractures (angle of $40-50^{\circ}$ with the hole). Finally, small channels could be observed below the indenter (Figure $3 \mathrm{~d}$ ). Enlargement (Figure 3e) reveals dissolution features that attest of solid-fluid reactions within these channels. These channels were active during the experiment and did not result from broken structures stuck onto the indenter and pulled out with its removal at the end of the experiment.

[30] Displacement rate versus stress measurements are represented in Figure 4 for four types of experiments described below. In all the cases, we distinguish samples with few evidence of dissolution around the hole and without any loss of weight (blue squares), from samples with significant evidence of dissolution on the whole free face of the sample and $10-30 \%$ loss of weight (red diamonds). There is clear evidence that when there is significant free face dissolution on the sample, the displacement rate of the indenter is higher than when the free face is not pitted by dissolution. We will see in the discussion section that this effect is probably not related to stress but more likely linked to the evolution of the pressure and temperature conditions with time.

[31] Figure $4 \mathrm{a}$ displays the results using synthetic quartz indented at $360^{\circ} \mathrm{C}$ and $120 \mathrm{MPa}$ fluid pressure. The saturated solution was injected in the pressure vessel after applying the stress on the indenter. The indenter was perpendicular to the quartz $\mathrm{m}$ prismatic face (and therefore perpendicular to the c axis). Figures $4 b, 4 c$, and $4 d$ display the results using natural quartz crystals indented at $350^{\circ} \mathrm{C}$ and $20 \mathrm{MPa}$ fluid pressure, with various orientations of the indenter versus quartz $\mathrm{c}$ axis and different ways to fill the solid/fluid/interface. Figures $4 \mathrm{~b}$ and $4 \mathrm{c}$ display the results when the saturated solution was poured on the sample before stress was applied. Figure $4 \mathrm{~b}$ gives the results with the indenter perpendicular to the basal plan of the quartz (parallel to the $\mathrm{c}$ axis). Figure $4 \mathrm{c}$ shows the results for the indenter perpendicular to the quartz $\mathrm{m}$ prismatic face (perpendicular to the c axis). Figure $4 d$ displays the results when a saturated solution was injected in the pressure vessel after applying the stress, the indenter being perpendicular to the quartz $\mathrm{m}$ prismatic face. Finally, Table 1 gives all the control parameters and results for the whole experimental data set.

\section{Discussion}

[32] The effects of the various parameters are discussed in order to build the best fitting pressure solution creep law.

\subsection{Effect of the Nature of the Fluid, Duration of the Experiment, and Diameter of the Indenter}

[33] When using dry contacts, the indenters did not leave any indenting evidence. When using quartz saturated water 

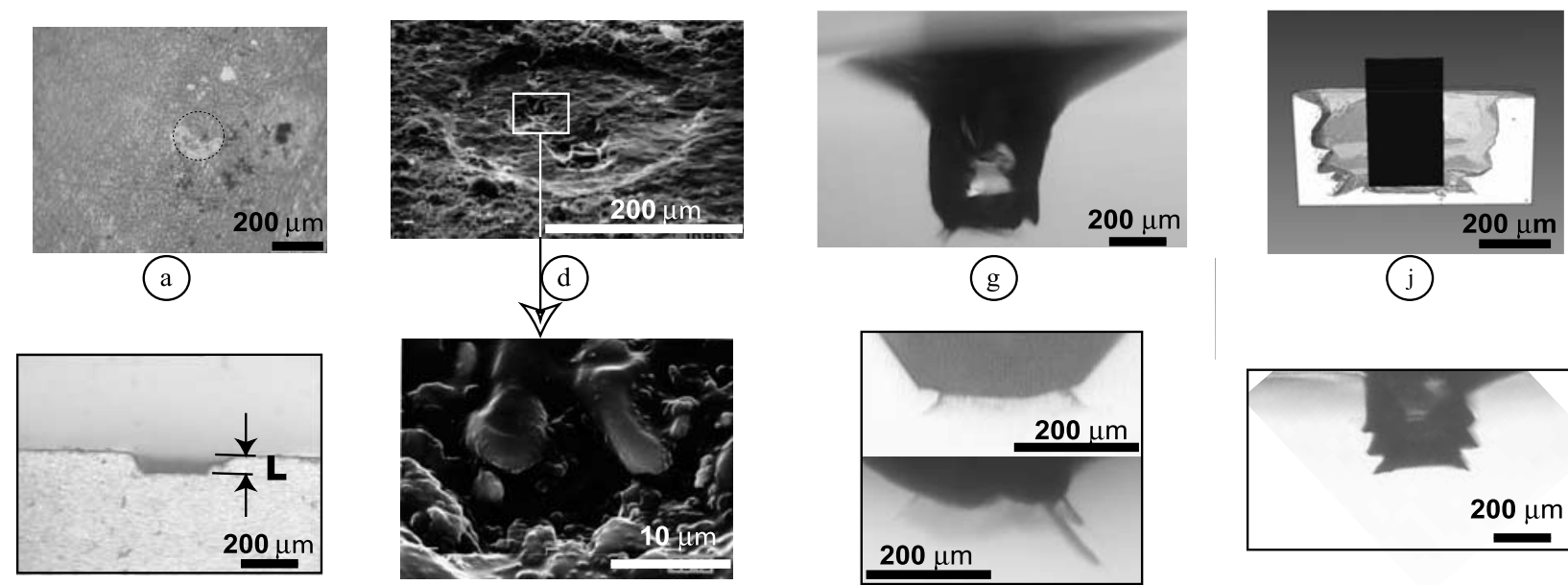

(a)

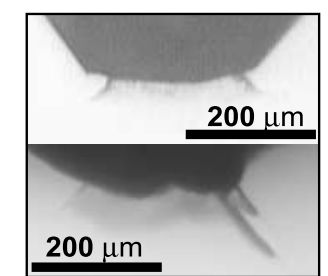

(e)
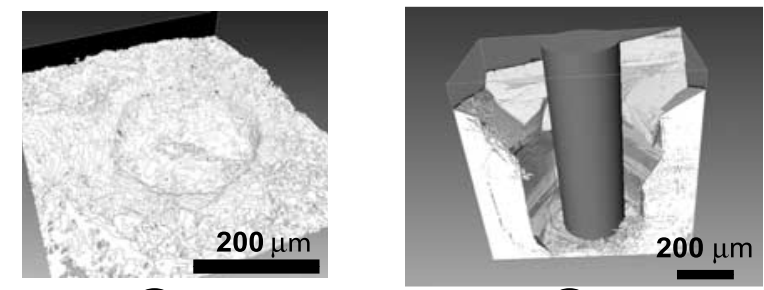

(b)

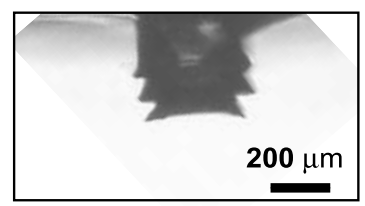

(b) (c)
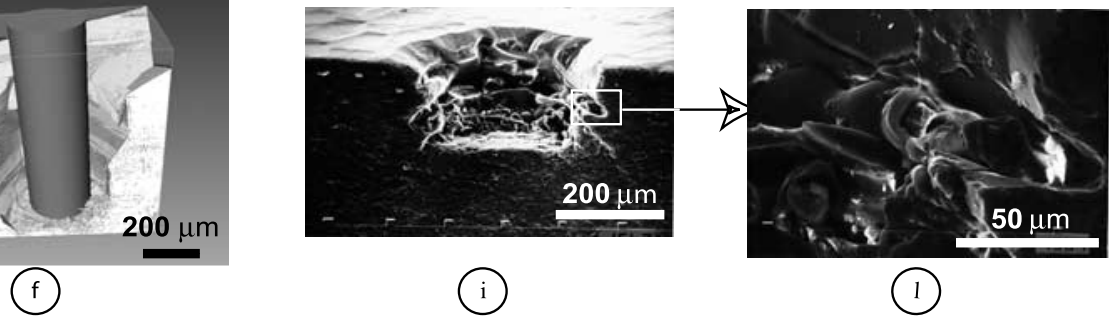

(i)

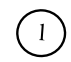

Figure 3. Various shapes and microstructures of pressure solution indented holes in quartz: $T=350^{\circ} \mathrm{C}$, $P_{f}=20 \mathrm{MPa}$ (natural) and $T=360^{\circ} \mathrm{C}, P_{f}=120 \mathrm{MPa}$ (synthetic), $\Delta \sigma=\left(\sigma_{\text {axial }}-P_{f}\right)$. See Table 1 for details. (a) NQ00-2, indentation with water, (b) NQ11-3 and (c) SQ17, low-stress dissolution holes whose diameter is very close to the indenter diameter; (d) NQ6-3: dissolution hole with evidence of a small channel under the indenter with (e) dissolution features within this channel, (f) and (g) NQ17-2, dissolution hole larger than the indenter diameter (X-ray microtomography and optical views, respectively); (h) NQ15-3 and SQ14, evidence of "crown shape" fractures developed below the indenter; (i) and (1) NQ4-2, dissolution hole larger than the indenter diameter with evidence of branched corrosion fractures with (Figure 31) network of fluid inclusions, (j) and (k) NQ15-1, dissolution hole with evidence of branched corrosion fractures (X-ray microtomography and optical views, respectively).

solution, even with very long duration ( 7 months as in Figure 3a), the indenting effect was negligible and, consequently, no significant hole depth could be measured. Conversely, with the $\mathrm{NaOH} 1 \mathrm{~mol} \mathrm{~L}^{-1}$ saturated solution, the displacement rates were measurable and clearly increased with stress. This shows the crucial effect of the solubility of the solid in solution for pressure solution experiments [Gratier and Guiguet, 1986]. This also confirms that increasing the solubility is one of the most efficient methods to activate pressure solution.

[34] Short durations (days) never allowed measurable hole to develop. The smallest holes (10 $\mu \mathrm{m}$ deep) were obtained after a couple of weeks only. With the same conditions, the depth of the hole increased with time. Consequently, we confidently assume constant displacement rate with time and a steady state process of dissolution.

[35] The use of diameter larger than $200 \mu \mathrm{m}$ never allowed measurable hole to develop. However, as the size of the dead weight was limited in the vessel (maximum $1200 \mathrm{~g}$, corresponding to a stress of $375 \mathrm{MPa}$ for a $200 \mu \mathrm{m}$ diameter indenter), this parameter is difficult to interpret as an increase of diameter led to a significant decrease of stress.

\subsection{Effect of Surface Roughness}

[36] The data show a large scatter of displacement rates for the same stress values, even using the same experimental procedure (Figure 5a). From the microstructures observations, several effects are possible: (1) effect of the temporary change of saturation during the experiment due to experimental temperature pressure perturbations, (2) effect of the roughness of the dissolution surface that evolves with time or stress, and (3) effect of microfractures and channels that develop under the indenter.

[37] The root-mean-square (RMS) of the roughness of the quartz below the indenter was calculated using the white light interferometry data. RMS values for 16 samples are plotted in Figures 5b, 5c, and 5d versus three parameters, the displacement rates, the duration of the experiment and the stress on the indenter, respectively. 

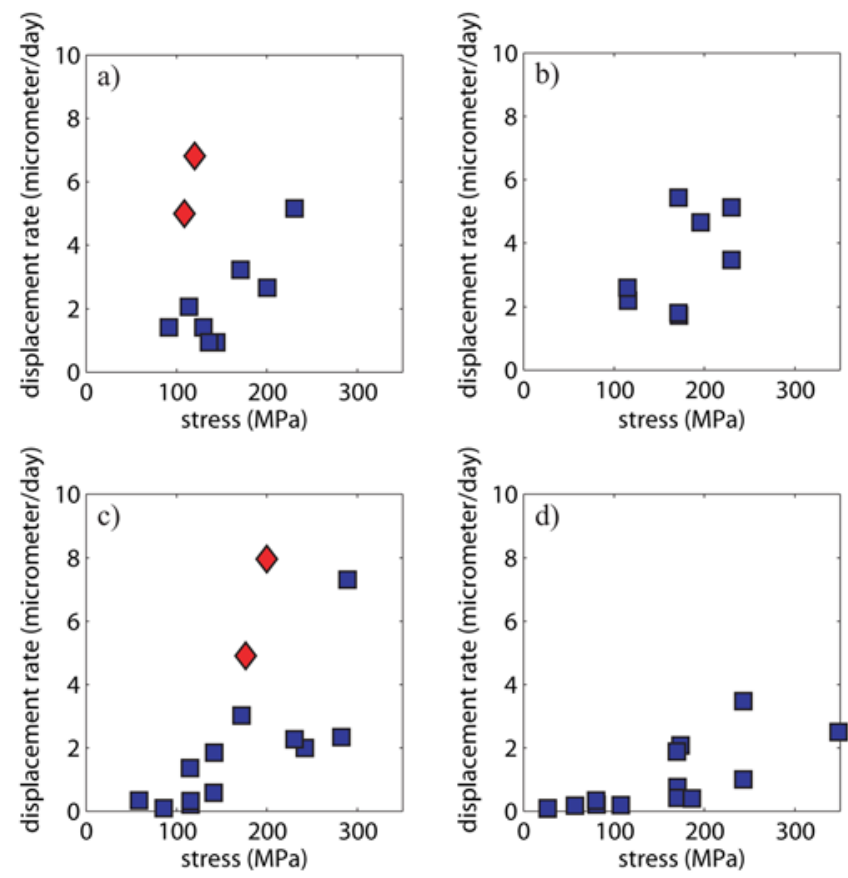

Figure 4. Displacement rate versus stress plot of the indenter experiments. Red diamonds indicate samples with significant evidence of dissolution around the hole (10$30 \%$ loss of weight). Blue circles indicate samples with few evidence of dissolution around the hole (no loss of weight). (a) Synthetic quartz, saturated solution on sample after applying stress (stress-then-fill procedure), dissolution along the $\mathrm{m}$ prismatic face (parallel to the $\mathrm{c}$ axis). (b) Natural quartz, saturated solution on sample before applying stress (fill-then-stress procedure), dissolution along the basal plane (perpendicular to the $\mathrm{c}$ axis). (c) Natural quartz, saturated solution on sample before applying stress, dissolution along the $\mathrm{m}$ prismatic face. (d) Natural quartz, saturated solution on sample after applying stress, dissolution along the $\mathrm{m}$ prismatic face.

[38] A first observation is that the two samples that exhibit large dissolution features around the indenter have the two highest RMS values. As already pointed out, such samples present abnormally high displacement rates due to temporary change of temperature and pressure. In case of electric power supply breakdown, leading to a drastic decrease of temperature and pressure, the solution equilibrated at room temperature by local deposition. Then, when the heating was reestablished, local dissolution accommodated the reequilibrating at higher temperature.

[39] Displacement rates are shown to increase with roughness from a general point of view (Figure 5b) and from the comparison of samples submitted to the same stress value (Figure 5a). This may be so because a larger roughness increases the diffusion flux along the fluid phase below the indenter. Conversely, the roughness slightly decreases with the duration of the experiment (Figure 5c). This is in agreement with experiments on halite crystals, where the decrease of the indentation rate was related to the smoothing of the interface [Dysthe et al., 2003]. Finally, the relation between stress and roughness is not obvious
(Figure 5d). The large variability of data implies that other effects could have contributed to the roughness variability. One possibility is the local dissolution promoted by dislocation defaults that was found to trigger microstylolites in quartz [Gratier et al., 2005] and to increase the roughness of dissolved areas. The variability of the results seems to be a characteristic property of the dissolution process. The question of whether dissolution surfaces are inherently unstable because of stress effect that promotes gain in the total elastic energy [Bonnetier et al., 2007] or very sensitive to local heterogeneity of the solid [Brouste et al., 2007; Renard et al., 2004; Schmittbuhl et al., 2004] remains a matter of debate.

\subsection{Effect of Microfractures and Channels in the Contact}

[40] Some samples exhibit reverse crown-shaped fractures under the indenter that are always associated with a dissolution hole larger than the indenter diameter (Figure $3 \mathrm{~g}$ ). First, we must compare the geometry of these fractures with the stress distribution below and around the indenter. As can be seen in Figure 1c, the effect of normal stress at the solid-fluid interface is restricted to the contact area between the indenter and the crystal, with maximum values along the boundary of the indenter. Conversely, strain energy promoted by the indenting extends far away from the indenter (as $r^{-1 / 2}$, where $r$ is the distance from the indenter). The 3-D shape of reverse crown-shaped fractures (Figure 3h) matches rather well the 2-D axis symmetrical distribution of the maximum values of horizontal and shear stresses modeled using a finite element method (Figures 1d and 1e). Then, as conceptually explained in Figure 6a, such fractures may propagate by dissolution corrosion and be a site of free face dissolution. Successive development of "reverse crown-shaped" fractures is associated with the enlargement of the dissolution hole (Figure 6a). The mechanism for such successive development is not clear. That strain energy is able to drive dissolution away from the contact, even if it is several orders of magnitude below the effect of normal stress (see Figure 1c), may be related to the kinetics of the processes. Dissolution rates have similar values for the stressed areas under the indenter and for the free face areas away from the indenter, since they have the same final depth, with driving forces that are thousand times different. This can be explained if the limiting process of the dissolution is different below and around the indenter. The diffusion rate through the free fluid around the indenter is probably much faster than along the thin fluid phase trapped under stress below the indenter. Consequently the kinetics of free face reactions could be the limiting process for dissolution around the indenter. Conversely, diffusion could be the limiting process below the indenter (see discussion below). One must also notice that the effect of reverse crown-shaped fracture is different from the effect that was found for radial fractures crossing the contact area [Gratier, 1993]. Radial fractures, filled of free fluids and thousand time wider than the trapped fluid below the indenter [Gratier et al., 1999], create shortcuts for diffusion under the indenter that increase the diffusion flux out of the trapped fluid phase (Figure 6b). Conversely, reverse crown-shaped fractures (Figure 6c) do not increase the diffusion flux out of the trapped fluid phase. In this case, 

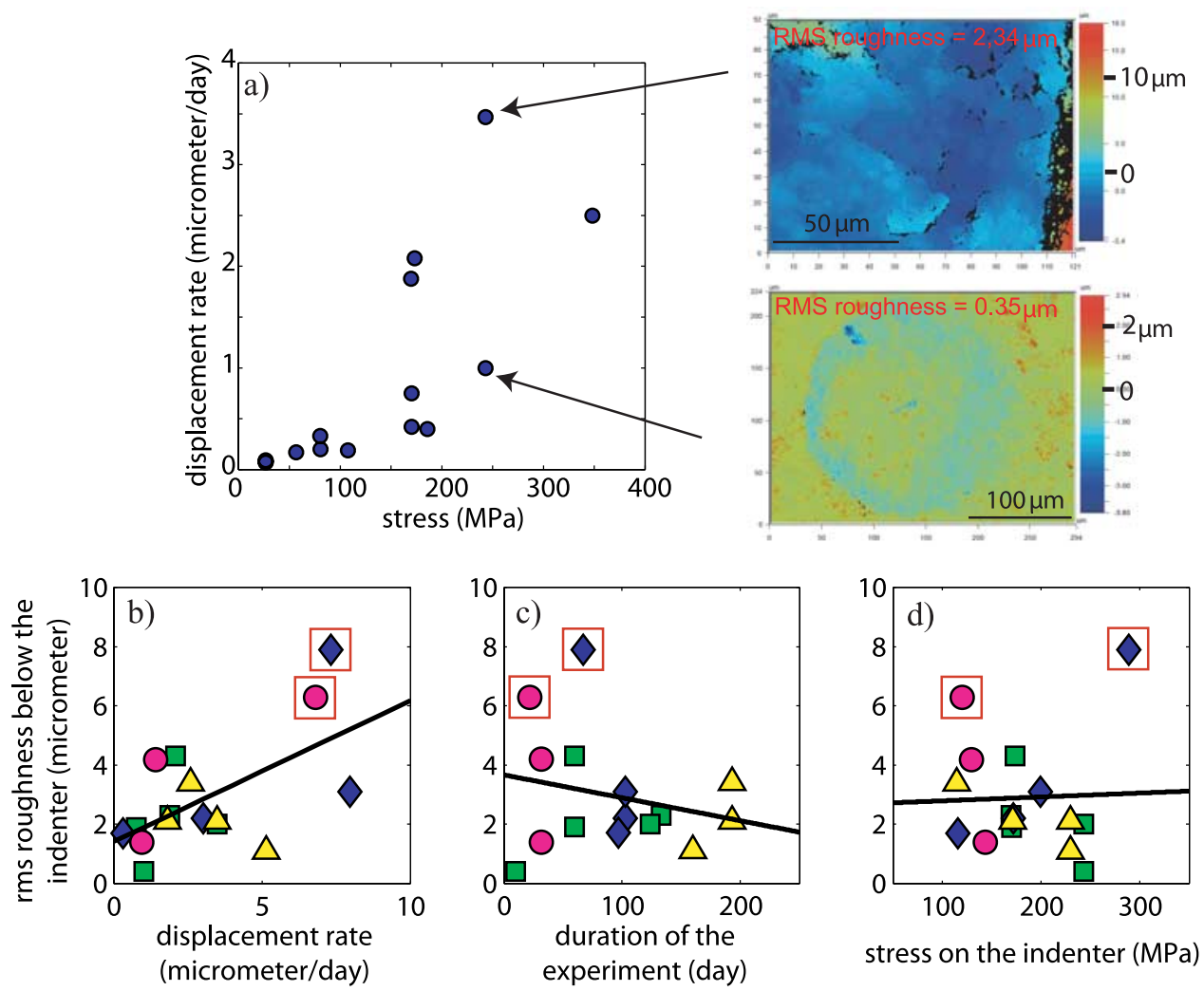

Figure 5. (a) Effect of roughness of the dissolution surface below the indenter on the displacement rate: the larger the roughness the higher the displacement rate, for similar stress values. Plot of the roughness of the dissolution surface below the indenter versus (b) displacement rate, (c) duration of the experiment, and (d) stress on the indenter. Blue diamonds indicate natural quartz, dissolution along the $\mathrm{m}$ prismatic face (parallel to the $\mathrm{c}$ axis), fill-then-stress procedure. Green squares indicate natural quartz, dissolution along the $\mathrm{m}$ prismatic face, stress-then-fill procedure. Pink circles indicate synthetic quartz, dissolution along the $\mathrm{m}$ prismatic face, stress-then-fill procedure. Yellow triangles indicate natural quartz, dissolution along the basal plane (perpendicular to the c axis), fill-then-stress procedure. Open red squares are samples with significant evidence of dissolution around the hole (10-30\% loss of weight).

as said above, dissolutions around and below the indenter go in parallel, but the true driving force that must be taken into account in creep law here is only the difference in chemical potential related to the difference in normal stresses (Figure 1c).

[41] Finally, we have observed that channels can locally develop under the indenter (Figure 3d). As said above, the diffusion flux through the free fluid within these channels is probably much larger than along the thin fluid phase trapped under stress below the indenter. Consequently, channels could play the same role of shortcut for diffusion than radial fractures. However, their spatial distribution is less regular. So and for the less, channels development could contribute to the variability of the data set as suggested by Gratz [1991] for the same type of effect related to microfractures development.

\subsection{Effect of Stress and Trapped Fluid Characteristics}

[42] We fitted exponential functions either on specific data sets corresponding to the four different experimental configurations (Figures $7 \mathrm{a}, 7 \mathrm{~b}, 7 \mathrm{c}$, and $7 \mathrm{~d}$ ) or on the whole data set (Figures $7 \mathrm{e}$ and $7 \mathrm{f}$ ). Such relation $\Delta x / \Delta t=$ $A\left(e^{0.013 \sigma_{n}}-1\right)$ was predicted by theoretical analysis [Dewers and Ortoleva, 1990; Weyl, 1959]. The numerical coefficient in the exponential $\left(0.013 \mathrm{MPa}^{-1}\right)$ is the product $3 V_{s} / R T$ (see equation (5)), with $\sigma_{n}$ expressed in MPa. Note, however, that because of the large noise in the experimental data, the determination coefficient $R$ is rather low $(R=0.47)$. Linear functions (black line) and power functions (blue line) are also plotted. For the whole data (Figure 7f), the best power function gives a stress exponent of 1.75 .

[43] All other experimental parameters being constant, when the saturated solution was injected after setting the stress on the indenter (Figure 7d), the displacement was slower than when the saturated solution was poured on the sample before loading the indenter (Figure 7c). However, this difference is not very large (1.7 faster when comparing the parameters of the fitted exponential functions). This result is in favor of a dynamic evolution of the trapped fluid phases under the indenter, at least at the beginning of the process since the fluid had to percolate under the indenter along the channels thanks to the rough surface. However, from the observation, one cannot distinguish between "island channel" [Cox and Paterson, 1991; Raj, 1982; Spiers and Schutjens, 1995] and "microcracking grain boundary" structures [den Brok, 1998; Gratz, 1991]. Such dynamic evolution is also in agreement with the observation of small channels along the bottom of the hole (Figure 3e). The 

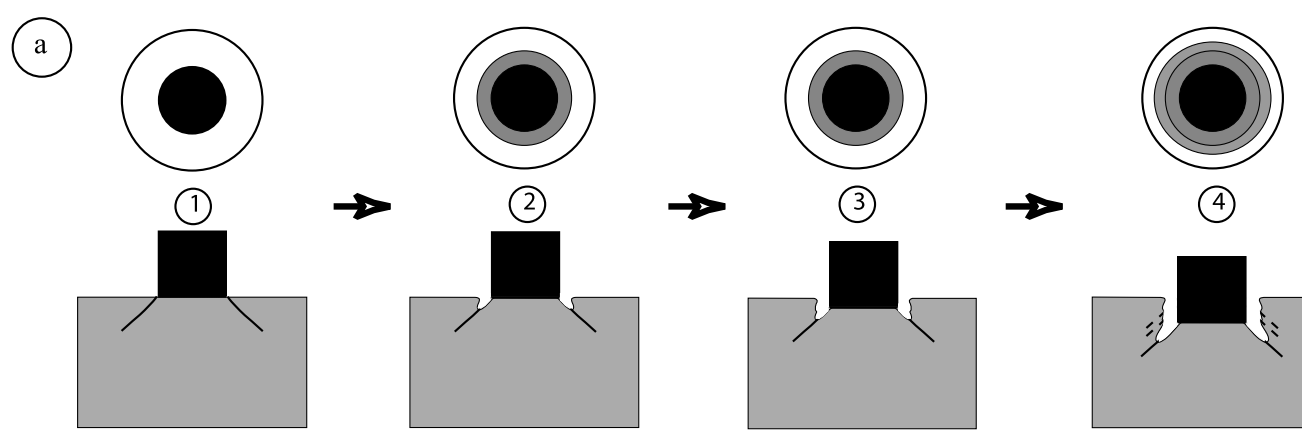

(4)
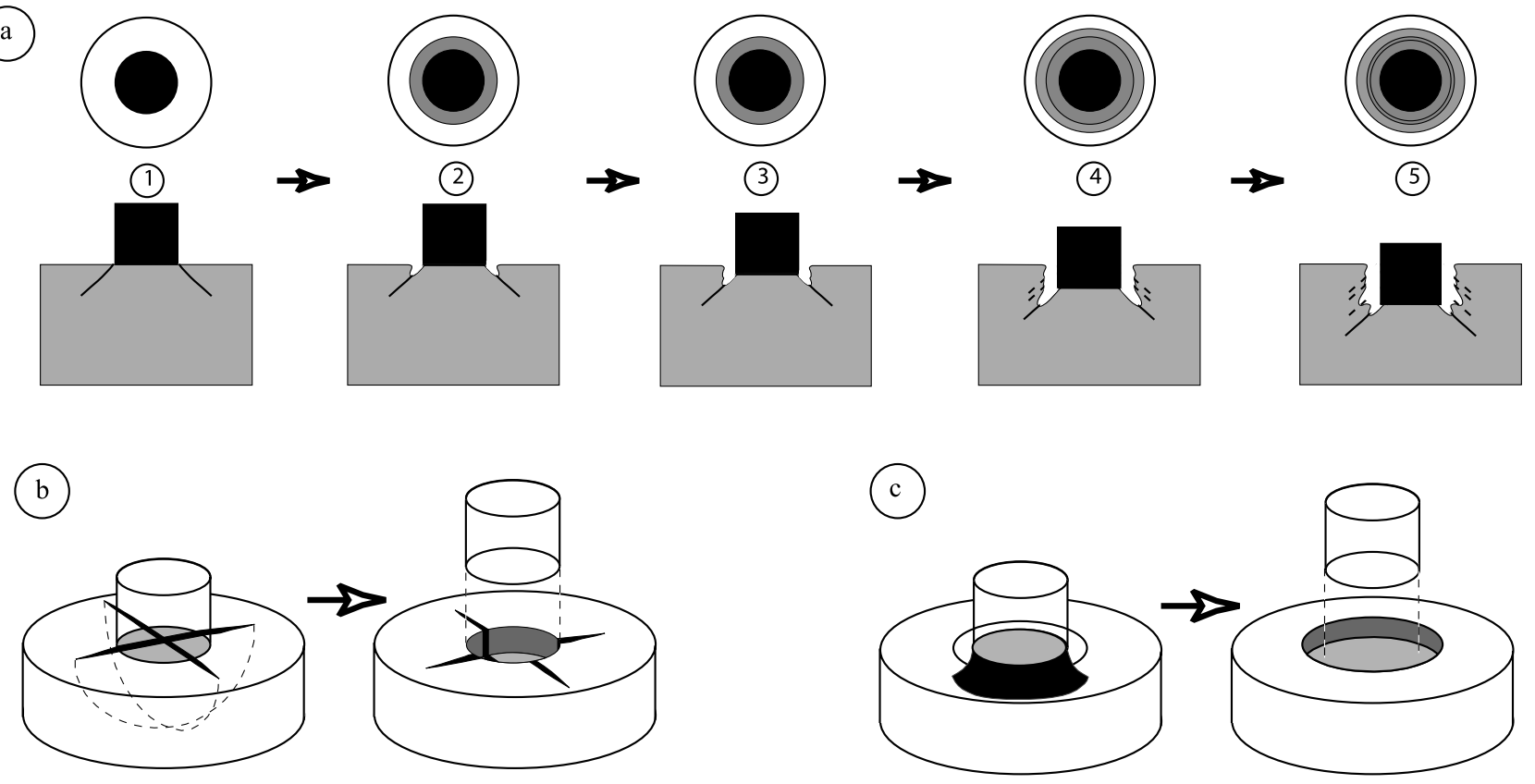

Figure 6. Relation between stress, fracture and dissolution below and around a loaded indenter. (a) Development of dissolution holes larger than the indenter diameter, with reverse crown shape fractures below the indenter that evolve to en echelon dissolved fracture as seen in Figure 3. The reverse crown shape fractures seen both in the axial view (top) and in cross sections (bottom) have an axial symmetry geometry, see also Figure 6c. (b) A 3-D schematic view of the effect of radial fractures [Gratier et al., 1999]: the displacement rate of the indenter is boosted since radial fractures (filled with a free fluid) act as shortcuts for the diffusion and the mean distance of mass transfer along trapped fluid is reduced. (c) Schematic 3-D view of the reverse crown shape fracture (black) and its effect on dissolution: the hole is larger than the indenter diameter but the displacement rate of the indenter is not significantly modified from experiment without such a fracture, since reverse crown shape fracture development do not increase the diffusion flux out of the trapped fluid phase.

modeling of pore evolution during compaction by pressure solution [Ghoussoub and Leroy, 2001] gives some clues of a possible mechanism for the fluid to penetrate a previously dry contact region by marginal dissolution along anticracks. Simulations by Gratz [1991] and Koehn et al. [2006] show that transitions could exist between the three main structures of grain boundaries: initial stressed solid-solid islands may be destroyed by anticracks and evolve toward wet grain boundary structure that can eventually evolve toward the development of a thin-film structure. Moreover, the dynamic evolution of island channel and grain boundary structures must be rather fast, at least at the beginning, with respect to the mean displacement rate of the indenter, in order to explain that this mean displacement rate of the indenter is not very sensitive to the way the contact is filled.

\subsection{Effect of the Type of Quartz and of Temperature and Fluid Pressure}

[44] The comparison of the results either with synthetic (Figure 7a) or natural quartz (Figure 7d) deformed in the same condition (stress-then-fill procedure, dissolution along the $\mathrm{m}$ prismatic face) shows a clear difference. The ratio of the prefactors of the exponential fitting functions for synthetic and natural quartz is about $4(0.28 / 0.07)$. Correcting the difference of temperature $\left(350^{\circ} \mathrm{C}\right.$ for natural quartz and $360^{\circ} \mathrm{C}$ for synthetic quartz) requires the knowledge of activation energy. Using two extreme values: either diffu- sion controlled process $\left(15 \mathrm{~kJ} \mathrm{~mol}^{-1} \mathrm{~K}^{-1}[\right.$ Rutter, 1976]) or reaction controlled process $\left(90 \mathrm{~kJ} \mathrm{~mol}^{-1} \mathrm{~K}^{-1}\right.$ [Gratz et al., 1990]), the prefactor of the fitting functions of synthetic quartz evolves from 0.28 (Figure $7 \mathrm{a}, \mathrm{SQ}-360^{\circ} \mathrm{C}$ ) to 0.27 or $0.21\left(350^{\circ}\right)$, respectively. Correcting the effect of fluid pressure is possible using the experimental solubility data. According to Kennedy [1950], Laudise [1970], and Regreny [1973], when using water or $\mathrm{NaOH}$ solutions $(0.5$ or $1 \mathrm{~mol} \mathrm{~L}^{-1}$ ), the ratio between quartz solubility at 120 and $20 \mathrm{MPa}$ vary from 1.5 to 2 . So the ratio of the factors fitting functions for synthetic and natural quartz could be reduced to about $2(0.135 / 0.07)$. Consequently, it remains a difference between natural and synthetic quartz that have been deformed in the same conditions (dissolution on the prismatic $\mathrm{m}$ face, stress-then-fill procedure) that could be linked to the evolution of the geometry of the diffusion pathway with time under the indenter. The progressive development of the channel and island network that is needed at the beginning of the dissolution with the stress-then-fill procedure may be slightly faster with synthetic than with natural quartz or the geometry of trapped fluid phases may be slightly different.

\subsection{Effect of the Orientation of the Crystal (Quartz c Axis Versus Dissolution Surface)}

[45] All other control experimental parameters being constant, the displacement rate was slightly higher when 

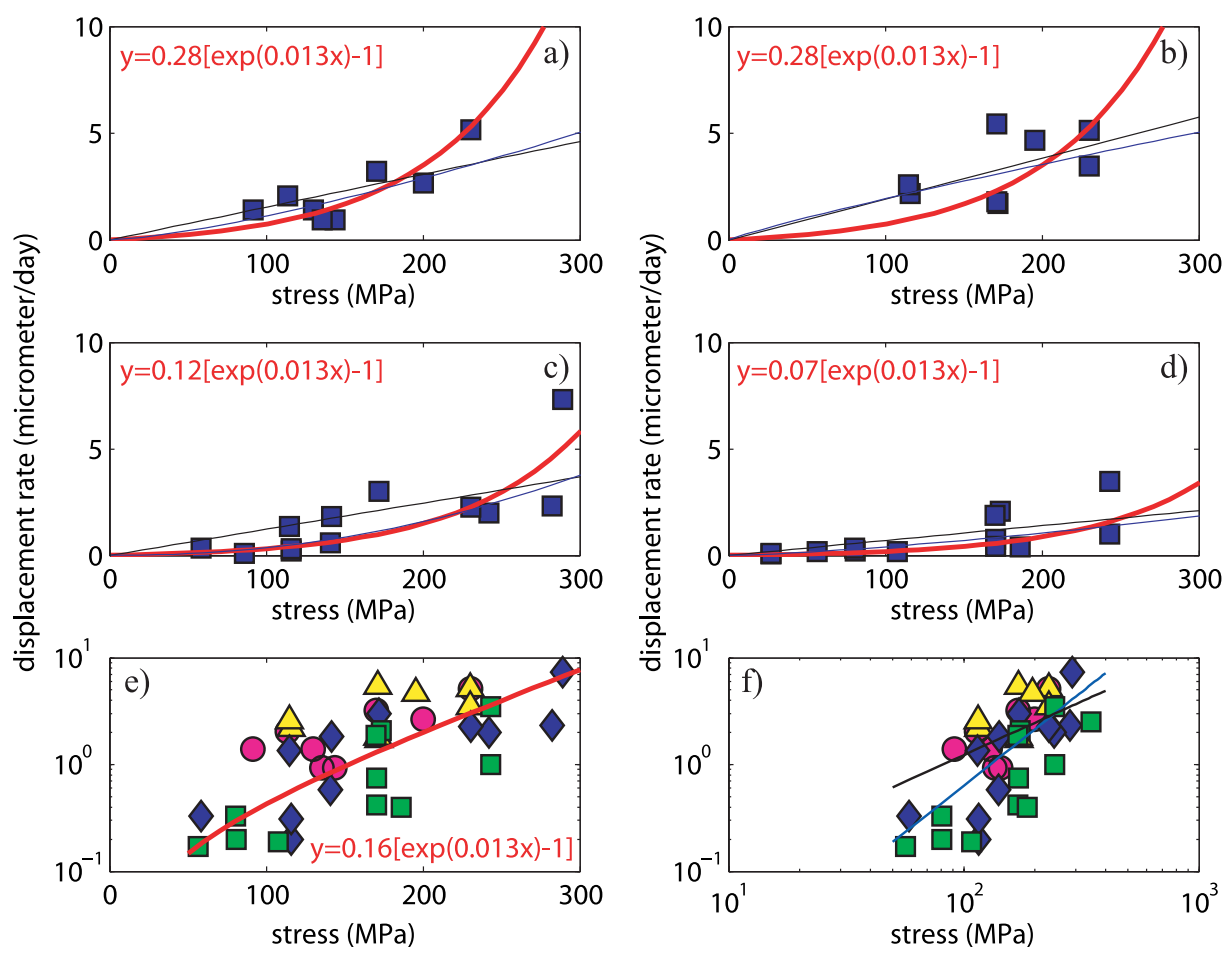

Figure 7. Displacement rate versus stress plot with various fitting relations: linear (black line), power (blue line) or an exponential function: $\Delta x / \Delta t=A\left(e^{0.013 \sigma_{n}}-1\right)$ the value 0.013 being the product $3 V_{s} / R T$ in equation (5) with $\sigma_{n}$ expressed in $\mathrm{MPa}$ (red line). In this case, the pressure solution exponential relations, derived by Dewers and Ortoleva [1990], are given on each plot with the power function (blue line) and linear function (black line). (e and f) Plots of the results with all the samples with the same various fitting relations (same legend). (left) Exponential function (red line) $\Delta x / \Delta t=0.16\left(e^{0.013 \sigma_{n}}-1\right)$ ( $\Delta x / \Delta t$ in $\mu \mathrm{m} \mathrm{d}^{-1}$, stress $\sigma_{n}$ in $\left.\mathrm{MPa}\right), R=0.47$. (right) Power function (blue line) and linear function (black line). The legend for the type of experiment is the same as in Figure 5.

the dissolution surface was perpendicular to the quartz $\mathrm{c}$ axis (basal surface, 0001, Figure 7b) than when the surface was parallel to the $\mathrm{c}$ axis (prismatic $\mathrm{m}$ face, $10 \overline{1} 0$, Figure $7 \mathrm{c}$ ). Moreover, evidence of free face dissolutions around the hole that are associated with higher displacement rates (see Figure 4) are more frequently observed with dissolution along the basal surface. Consequently, it is difficult to separate the two effects. However, the difference of displacement rates is not very large (2.3 faster for the basal surface when comparing the fitted exponential function factors).

[46] According to Regreny [1973] the growth rate of the basal plane in $\mathrm{NaOH}$ solution is 10 to 50 times larger than for the prismatic $\mathrm{m}$ face, and therefore larger than the factor 2.3 we measured. Iwasaki et al. [1997] measured the growth rate anisotropy of synthetic quartz grown in $\mathrm{Na}_{2} \mathrm{CO}_{3}$ solution and they found that the ratio between the growth rate of the basal plane and the prismatic $\mathrm{m}$ face is around 60 . The ratio between the growth rate of the rhomb $\mathrm{r}$ face and the prismatic $\mathrm{m}$ face is close to 10 . If the displacement rates were controlled by the growth kinetics, the same difference should be observed in the indenter experiments. This is not the case.

[47] Dissolution rate anisotropy is not so well known; however, Gratz and Bird [1993] measured the dissolution rate difference between the rhomb $\mathrm{r}$ face and the prismatic $\mathrm{m}$ face and found a ratio close to 2 . Even if the dissolution surface was oriented at $45^{\circ}$ of the rhombs faces, one may find other arguments than crystallographic orientation for a control by dissolution. These arguments are related to previous studies performed on the change of the shape of fluid inclusions due to both effects of temperature and internal pressure [Gratier and Jenatton, 1984]: the change of shape of a fluid inclusion from elongated (cigar shape) to more spherical (euhedral shape), driven by minimization of surface energy, was found to be controlled by dissolution kinetics. The difference with indenter studies is that diffusion occurs in the free fluid of the inclusion, instead of occurring along a trapped fluid phase under stress. Such experimental change of shape of fluid inclusions allow calculation of the dissolution rate parameter $k$ that appears in the displacement rate versus stress relation (equation (2)) when dissolution is rate controlling. A value of $2.7 \times$ $10^{-3} \mathrm{~mol} \mathrm{~m} \mathrm{~s}^{-1}$ [Gratier and Jenatton, 1984] was obtained for the kinetics constant $k$ when using the same saturated solution as in the indenter experiments. Using indenter displacement rate versus stress data (Figure 7), one may estimate the displacement rate if dissolution was the rate controlling step. Using a differential stress of $200 \mathrm{MPa}$, this displacement velocity should be $5 \times 10^{-8} \mathrm{~m} \mathrm{~s}^{-1}$, much larger than the experimental value close to $4 \times 10^{-11} \mathrm{~m} \mathrm{~s}^{-1}$. This large difference is in favor of a diffusion-limited process. This is also in agreement with the observation that the displacement rates of the surface below the indenter and 


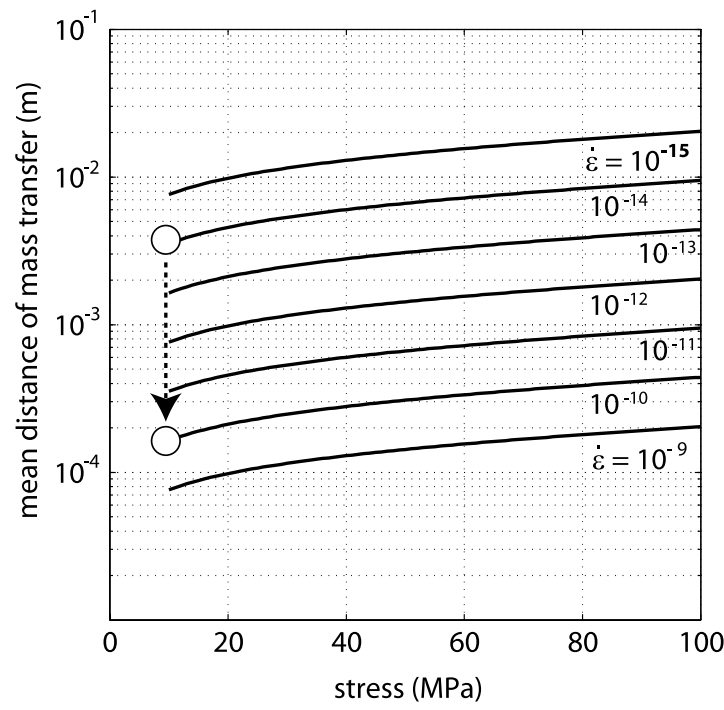

Figure 8. Deformation map of pressure solution creep for natural quartz deformed at $350^{\circ} \mathrm{C}, 250 \mathrm{MPa}$, modeled using the mean exponential fitting relation $\Delta x / \Delta t=0.16\left(e^{0.013 \sigma_{n}}-1\right)$ obtained for the whole experimental data set (Figure 7e) but with a value of the solubility of quartz in water $=0.03 \times$ $10^{3} \mathrm{~mol} \mathrm{~m}^{-3}$ instead of $0.73 \times 10^{3} \mathrm{~mol} \mathrm{~m}^{-3}$ for the experiments. The strain rate for natural quartz at $350^{\circ} \mathrm{C}$ and $250 \mathrm{MPa}$ is found to be $\varepsilon=\Delta d / d \Delta t=3 \times 10^{-21}\left(e^{0.013 \sigma_{n}}-\right.$ $1) / d^{3}$, with $\sigma_{n}$ expressed in $\mathrm{MPa}, \Delta d=\Delta x$ and $d$ in $\mathrm{m}$. Evolution of strain rates includes the effects of stress and mean distance of mass transfer (which could be the grain size or the spacing between fractures in natural systems). The dotted line indicates the possible deformation path from a slow deformation to a fast one only triggered by fracture development that change the mean distance of mass transfer. This may be related to earthquakes that could thus trigger postseismic pressure solution creep.

the free face outside the indenter have similar values (same depth, Figure 3), whereas the driving force ratio is close to one thousand. Kinetics of free face reactions around the indenter are probably driven by reaction rate whereas dissolution along the stressed fluid phase is diffusion controlled. Some other studies [Schutjens, 1991; Niemeijer and Spiers, 2002] are rather in favor of dissolution rate control, based on the high activation energy of the deformation they measured experimentally. The difference with our work is that such studies were done on porous aggregates. It is possible that in the first stages of aggregates compaction, free face reaction may control the pressure solution process.

[48] When considering the displacement versus stress law proposed in equation (5), most parameters are known: $c$ is quartz concentration in solution $(\mathrm{NaOH} 1 \mathrm{M})=0.73 \times$ $10^{3} \mathrm{~mol} \mathrm{~m}^{-3} ; V_{s}$ is molar volume of the solid equal to $2.2 \times$ $10^{-5} \mathrm{~m}^{3} \mathrm{~mol}^{-1} ; R=8.32 \mathrm{~J} \mathrm{~mol}^{-1} \mathrm{~K}^{-1} ; T=623 \mathrm{~K} ; d=$ $200 \times 10^{-6} \mathrm{~m}$; and $\sigma$ is the stress $(\mathrm{Pa}), \lambda=8[$ Dewers and Ortoleva, 1990]. The only unknown parameters are $D$ and $w$, which cannot be separated from the results of the experiments. When integrating all indenter data (Figure 7e), and using the experimental fitting function relation $\Delta x / \Delta t=0.16\left(e^{0.013 \sigma_{n}}-1\right)$, the product $D w$ is equal to $5.7 \times 10^{-19} \mathrm{~m}^{3} \mathrm{~s}^{-1}$ at $350^{\circ} \mathrm{C}$. Using extreme values of the fitting functions (Figure $7 \mathrm{~b}$ versus Figure $7 \mathrm{~d}$ data) give values of $D w$ ranging from 2.5 to $10 \times 10^{-19} \mathrm{~m}^{3} \mathrm{~s}^{-1}$. When using $D$ values from literature $\left(D=10^{-10} \mathrm{~m}^{2} \mathrm{~s}^{-1}\right.$ at $350^{\circ} \mathrm{C}$ ), the mean thickness of the trapped fluid phase is about $6 \mathrm{~nm}$, with extreme values ranging from 2 to $10 \mathrm{~nm}$ ( 8 to 40 water molecules thickness).

\section{Application to Transitory Creep and Sealing Processes in Active Faults}

[49] Two applications are proposed in Figures 8 and 9. A deformation map of pressure solution creep for natural quartz deformed at $350^{\circ} \mathrm{C}$ and $250 \mathrm{MPa}$ fluid pressure, in water, is modeled using the experimental data:

$$
\dot{\varepsilon}=\Delta d / d \Delta t=8 D w c V_{s}\left(e^{3 \sigma_{n} V_{s} / R T}-1\right) / d^{3}
$$

Equation (6) is the proposed creep law. The parameters are the same as in equation (5) for the indenter, with $c$ the solubility of quartz in water being $0.03 \times 10^{3} \mathrm{~mol} \mathrm{~m}^{-3}$; $\Delta d=\Delta x, d$ is both the distance of mass transfer along the thin-trapped fluid phase (basal radius of the cylindrical indenter) and the size of a deformed element (height of this element). The main problem with the application of such creep law in natural deformation is the value chosen for $d$. Most often $d$ is considered to be the grain size. However, even if Elliot [1973] showed convincing evidences of diffusive mass transfer at grain scale in metamorphic rocks, the mean distance of mass transfer along trapped fluid phase is commonly not the grain scale in upper crust rocks. Most often mass transfer occurs from transgranular surfaces as stylolites or solution cleavage to pores or sealed veins without a clear connection with grain size. We therefore propose here that fracture spacing may be the mean distance of mass transfer along trapped fluid and take this parameter for $d$. Figure 8 shows the evolution of strain rate with both effect of stress and the mean distance of mass transfer. As pointed out long time ago, the distance of mass transfer is the crucial parameter of pressure solution creep laws for a diffusion-limited process [Elliot, 1973]. This allows predicting how an earthquake can trigger pressure solution creep due to the drastic decrease in the distance of mass transfer associated with fracturing and fragmentation processes. The spacing between microfractures needs to be used in the creep relation (equation (6)). During an earthquake, a drastic reduction of the spacing between fractures occurs. This variation could trigger postseismic creep, as shown on Figure 8, where a drop of $d$ from $3 \mathrm{~mm}$ down to $200 \mu \mathrm{m}$ may increase the strain rate by pressure solution creep up to 4 orders of magnitude. In Figure 8 , the dotted line indicates the possible deformation path from a slow deformation creep (before an earthquake) to a faster creep, only triggered by fracture development as suggested by Gratier and Gueydan [2007]. Following this idea, pressure solution creep may be identified as the slow creep mechanism recognized in post seismic creep that cannot be modeled with the common rate-and-state law [Johnson et al., 2006].

[50] However, pressure solution postseismic creep process cannot be stable with time since fractures progressively 


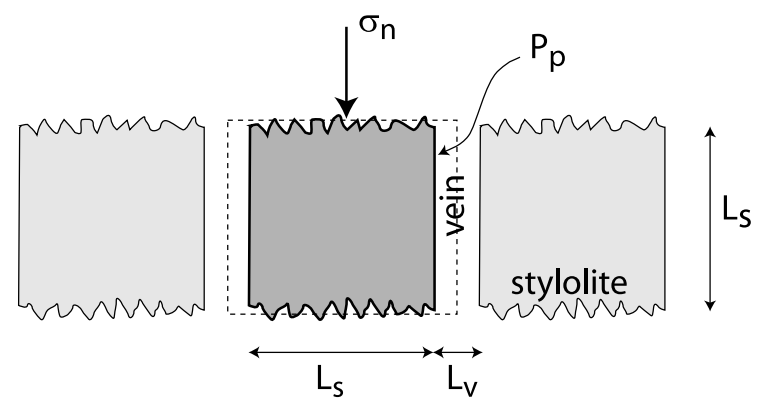

a)

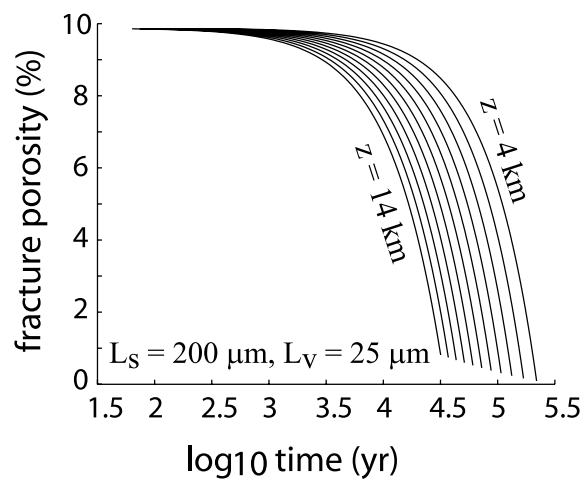

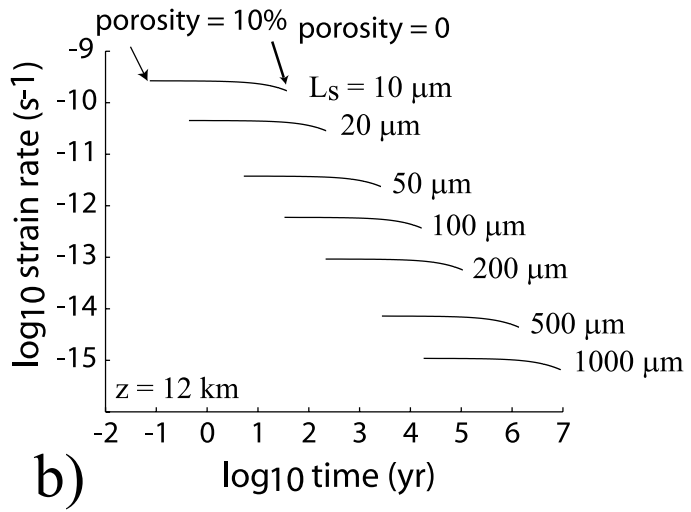

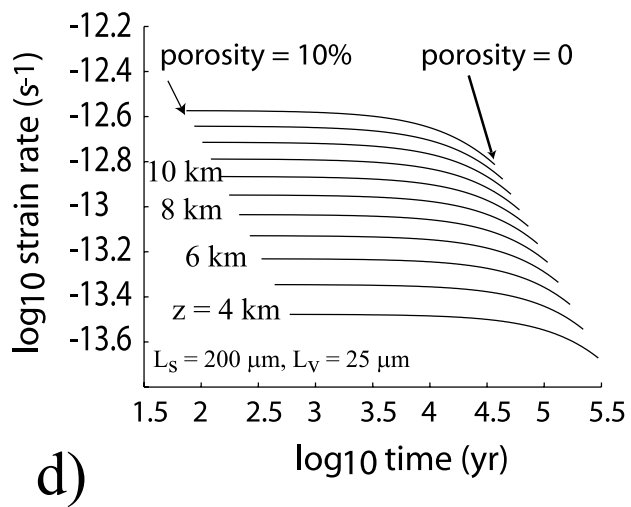

Figure 9. Model of deformation by pressure solution creep into a fault. (a) After an earthquake, the fault gouge is fragmented into pieces of size $L_{s}$, separated by empty veins of width $L_{v}$. With time, pressure dissolution occurs along the grain contacts (also called here stylolites), where stress is concentrated, and the soluble elements fill the vein by precipitation [see also Renard et al., 2000]. This mechanism induces permanent strain. We consider here deformation on a single fragment (dashed box). (b) Evolution of strain rate with time. As the fracture are progressively sealed the strain decrease with a near exponential function. The thermodynamic conditions are those at about $12 \mathrm{~km}$ depth. For small systems $\left(L_{s}\right.$ close to $10 \mu \mathrm{m}$ ), the characteristic time of the sealing is 0.1 to 1 year, whereas it reaches million of years for fragments close to $1 \mathrm{~mm}$ size. This large variation of pressure solution time scales in the fault could explain why slow relaxations are observed, even for long times after an earthquake. (c) Fracture porosity and (d) strain rate time evolution for $L_{s}=200 \mu \mathrm{m}$, and $L_{v}=25 \mu \mathrm{m}$, at various depths.

seal due to dissolution along stylolites or cleavage. This must lead to a progressive decrease of the strain rate due to the progressive increase of the distance of mass transfer and the progressive increase of the solid surface that supports the stress. We have modeled this situation, using the same approach as by Renard et al. [2000]. Assuming that during an earthquake, the rock is fragmented and fracture porosity is created, the postseismic phase would correspond to the slow healing of this damage, as measured by Vidale and $L i$ [2003]. We consider rock fragments with a size $L_{s}$ (Figure 9a), separated by open fractures with an aperture $L_{v}$. At the fragment contacts, stress is concentrated, inducing stress-enhanced dissolution along stylolitic surfaces. The dissolved material is transported by diffusion to the open veins where precipitation occurs. With time, dissolution along the stylolites induces a permanent strain, whereas the porosity slowly decreases by fracture sealing.

[51] Using equations (7)-(10) of Renard et al. [2000], it is possible to calculate the strain evolution using the indenter experimental data. We consider here a model system as in Figure 9a, located at $12 \mathrm{~km}$ depth, where the temperature is equal to $350^{\circ} \mathrm{C}$ (like in the indenter experiments), the pore pressure is $120 \mathrm{MPa}$, and the confining pressure is $260 \mathrm{MPa}$. Using quartz solubility at this depth, a water film thickness of $6 \mathrm{~nm}$, and the contact diffusion constant deduced from the indenter experiments, we calculated the strain rates for different system sizes by varying $L_{s}$ between $10 \mu \mathrm{m}$ and $1 \mathrm{~mm}$, and assuming a postearthquake porosity of $11 \%$ (the values of $L_{s}$ and porosity are sufficient to fix the initial fracture aperture $L_{v}$, see Figure 9a).

[52] Using an energy activation equal to $10 \mathrm{~kJ} \mathrm{~mol}^{-1}$, representative of a process limited by diffusion, and assuming lithostatic confining pressure in the rock, and hydrostatic fluid pressure in the fluid, the depth dependence of this deformation can also be calculated (Figures 9c and 9d). If we consider the time after the earthquake, during which the porosity has been raised arbitrarily to $11 \%$, the fractures close slowly with time, until the complete closure of the porosity. The time scales of this process depend only slightly on depth, through the dependence of quartz solubility on 
temperature and pressure, and through the dependence of diffusion on temperature. For a constant system size, this variation spans less than 1 order of magnitude for the strain rate or the porosity reduction (Figures 9c and 9d). Conversely, the time scale of pressure solution creep spans more than 6 orders of magnitude when the mean distance of mass transfer varies only over 3 orders of magnitude (Figure 9b), illustrating that this parameter is indeed the controlling factor for pressure solution creep. These simple calculations allow prediction of the progressive strengthening of the rocks that occurs, for example, after an earthquake [Vidale and $L i, 2003$ ] due to fracture sealing by pressure solution creep [Giger et al., 2007; Tenthorey and Cox, 2006].

[53] The damaging effect of an earthquake, when fragmenting the fault gouge and the neighboring damaged country rocks, should enhance deformation by a pressure solution creep mechanism during the postseismic period. Then, and always due to pressure solution process, the sealing of the fracture network progressively decreases the permeability and strengthens the fault rocks. Characteristic times of these transitory processes of creep and sealing are drastically dependent on the system size: grain size comminuting or fracture spacing.

\section{Conclusion}

[54] Experiments by an indenter technique provide a better understanding of pressure solution processes on quartz.

[55] 1. At limited differential stress $(25-350 \mathrm{MPa})$ and temperature conditions $\left(350^{\circ} \mathrm{C}\right)$ representative of middle to upper crust deformation, the use of highly soluble solutions $\left(\mathrm{NaOH} 1 \mathrm{~mol} \mathrm{~L}^{-1}\right)$ is required in order to obtain significant dissolution holes $(5-500 \mu \mathrm{m})$ for laboratory duration.

[56] 2. Displacement rates of the indenter increase with the roughness of the dissolution surface. Roughness slightly smoothes with time and is rather independent of stress. Because of the relatively large variability of dissolution roughness, the question of whether dissolution surfaces are inherently unstable due to stress effect or very sensitive to local heterogeneity remains a matter of debate.

[57] 3. As mean displacement rates are not very different when pouring the solution before loading the indenter (initial wet contact) or when injecting solution after loading (initial dry contact), the development of a trapped fluid phase below the indenter must imply a relatively fast dynamic evolution, at least at the beginning of the experiment, that allow fluid penetration into a previously dry contact region by marginal dissolution.

[58] 4. From comparison of reaction kinetics in literature with our experiments conducted on variously oriented quartz surfaces (basal plane or $m$ face), we found that the displacement rate of the indenter is controlled by diffusion along a thin fluid phase trapped in the contact. Conversely, the dissolution around the indenter, driven by strain energy, is controlled by free surface reaction kinetics.

[59] 5. Displacement rate of the indenter is exponentially activated by stress as theoretically predicted. An unknown parameter (diffusion coefficient times width of fluid phase) is evaluated to range from $2.5 \times 10^{-19} \mathrm{~m}^{3} \mathrm{~s}^{-1}$ to $10^{-18} \mathrm{~m}^{3}$ $\mathrm{s}^{-1}$. When using diffusion coefficient values from literature $\left(\mathrm{D}=1 \times 10^{-10} \mathrm{~m}^{2} \mathrm{~s}^{-1}\right.$ at $\left.350^{\circ} \mathrm{C}\right)$, the mean thickness of the trapped fluid phase ranged from 2 to $10 \mathrm{~nm}$.
[60] 6. Use of these results for the modeling of pressure solution-fracturing interactions gives characteristic times of both transitory creep and sealing processes of quartz at depth during the seismic cycle. Pressure solution creep may be identified as the slow aseismic mechanism recognized in post seismic creep measurements and the slow sealing process that progressively strengthen the fault during the interseismic period.

[61] Acknowledgments. We thank C. J. Spiers and M. S. Paterson for their thoughtful reviews, R. Hellmann and D. Tisserand for their help, and L. Angheluta, J. Mathiesen, and D. Dysthe for helpful discussions.

\section{References}

Bérest, P., et al. (2004), Fluage du sel gemme sous très faibles charges, creep of rock salt under very small loadings, C. R. Geosci., 336, 13371344, doi:10.1016/j.crte.2004.09.005

Bonnetier, E., C. Misbah, F. Renard, R. Toussaint, and J. Gratier (2007), Are stylolitic surfaces inherently unstable surfaces? Insights from shape minimization considerations, Eos Trans. $A G U, 88(52)$, Fall Meet. Suppl., Abstract T43E-08.

Brouste, A. F., F. Renard, J.-P. Gratier, and J. Schmittbuhl (2007), Variety of stylolites morphologies and statistical characterization of the amount of heterogeneities in the rock, J. Struct. Geol., 29, 422-434, doi:10.1016/ j.jsg.2006.09.014

Cox, S., and M. Etheridge (1989), Coupled grain-scale dilatancy and mass transfer during deformation at high fluid pressures: Examples from Mount Lyell, Tasmania, J. Struct. Geol., 11, 147-162, doi:10.1016/ 0191-8141(89)90040-0.

Cox, S. F., and M. S. Paterson (1991), Experimental dissolutionprecipitation creep in quartz aggregates at high temperatures, Geophys. Res. Lett., 18, 1401-1404, doi:10.1029/91GL01802.

den Brok, S. W. J. (1998), Effect of microcracking on pressure-solution strain rate: The Gratz grain boundary model, Geology, 26, 915-918, doi:10.1130/0091-7613(1998)026<0915:EOMOPS>2.3.CO;2.

Dewers, T., and P. Ortoleva (1990), A coupled reaction/transport/mechanical model for intergranular pressure solution stylolites, and differential compaction and cementation in clean sandstones, Geochim. Cosmochim. Acta, 54, 1609-1625, doi:10.1016/0016-7037(90)90395-2.

Dysthe, D. K., F. Renard, J. Feder, B. Jamtveit, P. Meakin, and T. Jøssang (2003), High resolution measurements of pressure solution creep, Phys. Rev. E, 68, doi:10.1103/PhysRevE.68.011603.

Elliot, D. (1973), Diffusion flow law in metamorphic rocks, Geol. Soc. Am. Bull., 84, 2645-2664, doi:10.1130/0016-7606(1973)84< 2645:DFLIMR $>2.0 . \mathrm{CO} ; 2$.

Ghoussoub, J., and Y. M. Leroy (2001), Solid-fluid phase transformation within grain boundaries during compaction by pressure solution, J. Mech. Phys. Solids, 49, 2385-2430, doi:10.1016/S0022-5096(01)00012-6.

Gibbs, J. W. (1877), On the equilibrium of heterogeneous substances, Trans. Conn. Acad., 3, 108-248, 343-524.

Giger, S. B., E. Tenthorey, S. F. Cox, and J. D. Fitz Gerald (2007), Permeability evolution in quartz fault gouges under hydrothermal conditions, J. Geophys. Res., 112, B07202, doi:10.1029/2006JB004828.

Gratier, J. P. (1993), Experimental pressure solution of halite by an indenter technique, Geophys. Res. Lett., 20, 1647-1650, doi:10.1029/93GL01398.

Gratier, J. P., and J. F. Gamond (1990), Transition between seismic and aseismic deformation in the upper crust, in Deformation Mechanisms, Rheology and Tectonics, edited by R. J. Knipe and E. H. Rutter, Geol. Soc. Spec. Publ., 54, 461-473.

Gratier, J. P., and F. Gueydan (2007), Deformation in the presence of fluids and mineral reactions: Effect of fracturing and fluid-rocks interaction on seismic cycle, in Tectonic Faults: Agent of Change on a Dynamic Earth, edited by G. H. M. R. Handy and N. Hovius, pp. 319-356, MIT Press, Cambridge, Mass.

Gratier, J. P., and R. Guiguet (1986), Experimental pressure solutiondeposition on quartz grains: The crucial effect of the nature of the fluid, J. Struct. Geol., 8, 845-856, doi:10.1016/0191-8141(86)90030-1.

Gratier, J. P., and L. Jenatton (1984), Deformation by solution-deposition and reequilibration of fluid inclusions in crystals depending on temperature, internal pressure and stress, J. Struct. Geol., 6, 189-200.

Gratier, J. P., F. Renard, and P. Labaume (1999), How pressure-solution and fractures interact in the upper crust to make it behave in both a brittle and viscous manner, J. Struct. Geol., 21, 1189-1197, doi:10.1016/S01918141(99)00035-8.

Gratier, J. P., L. Muquet, R. Hassani, and F. Renard (2005), Experimental microstylolites in quartz and modeled application to natural stylolitic structures, J. Struct. Geol., 27, 89-100, doi:10.1016/j.jsg.2004.05.007. 
Gratz, A. J. (1991), Solution-transfer compaction of quartzites: Progress toward a rate law, Geology, 19, 901-904, doi:10.1130/00917613(1991)019<0901:STCOQP $>2.3$.CO;2.

Gratz, A. J., and P. Bird (1993), Quartz dissolution: Negative crystal experiments and rate law, Geochim. Cosmochim. Acta, 57, 965-976, doi:10.1016/0016-7037(93)90033-S.

Gratz, A. J., P. Bird, and G. B. Quiro (1990), Dissolution of quartz in aqueous basic solution $106-236^{\circ} \mathrm{C}$ : Surface kinetics of "perfect" crystallographic faces, Geochim. Cosmochim. Acta, 54, 2911-2922, doi:10.1016/0016-7037(90)90109-X

Guéguen, Y., and V. Palciauskas (1994), Introduction to the Physics of Rocks, Princeton Univ. Press, Princeton, N. J.

Hickman, S. H., and B. Evans (1991), Experimental pressure solution in halite: The effect of grain/interphase boundary structure, J. Geol. Soc. 148, 549-560, doi:10.1144/gsjgs.148.3.0549.

Iwasaki, F., H. Iwasaki, and Y. Okabe (1997), Growth rate anisotropy of synthetic quartz grown in $\mathrm{Na} 2 \mathrm{CO} 3$ solution, J. Cryst. Growth, 178, 648 652, doi:10.1016/S0022-0248(97)00132-2.

Johnson, K. M., R. Bürgmann, and K. Larson (2006), Frictional properties on the San Andreas Fault near Parkfield, California, inferred from models of afterslip following the 2004 earthquake, Bull. Seismol. Soc. Am., 96, S321-S338, doi:10.1785/0120050808.

Karcz, Z., E. Aharonov, D. Ertas, R. Polizzotti, and C. H. Scholz (2006), Stability of a sodium chloride indenter contact undergoing pressure solution, Geology, 34, 61-63, doi:10.1130/G21722.1

Kennedy, G. C. (1950), A portion of the system silica-water, Econ. Geol., $45,629-653$

Kingery, W. D., H. K. Bowen, and D. R. Uhlmann (1976), Introduction to Ceramics, 2nd ed., 1032 pp., John Wiley, New York.

Koehn, D., A. Malthe-Sørenssen, and C. W. Passchier (2006), The structure of reactive grain-boundaries under stress containing confined fluids, Chem. Geol., 230, 207-219, doi:10.1016/j.chemgeo.2006.02.026.

Laudise, R. A. (1970), Hydrothermal Synthesis of Single Crystals, PrenticeHall, Englewood Cliffs, N. J.

Le Guen, Y., F. Renard, R. Hellmann, E. Brosse, M. Collombet, D. Tisserand, and J.-P. Gratier (2007), Enhanced deformation of limestone and sandstone in the presence of high $\mathrm{P}_{\mathrm{CO} 2}$ fluids, J. Geophys. Res., 112, B05421, doi:10.1029/2006JB004637.

Lehner, F. K. (1990), Thermodynamics of rock deformation by pressure solution, in Deformation Processes in Minerals, Ceramics and Rocks, edited by D. J. Barber and P. G. Meredith, pp. 296-333, Unwin Hyman, London.

Lehner, F. K. (1995), A model for intergranular pressure solution in open systems, Tectonophysics, 245, 153-170, doi:10.1016/00401951(94)00232-X

Leroy, Y., and W. Heidug (1994), Geometrical evolution of stressed and curved solid-fluid phase boundary: 2. Stability of cylindrical pores, J. Geophys. Res., 99, 517-530, doi:10.1029/93JB02572.

Niemeijer, A. R., and C. J. Spiers (2002), Compaction creep of quartz sand at $400-600^{\circ} \mathrm{C}$ : Experimental evidence for dissolution controlled pressure solution, Earth Planet. Sci. Lett., 195, 261-273, doi:10.1016/S0012821X(01)00593-3.

Oelkers, E. H., P. A. Bjorkum, and W. M. Murphy (1996), A petrographic and computational investigation of quartz cementation and porosity reduction in North Sea sandstones, Am. J. Sci., 296, 420-452.

Paterson, M. S. (1973), Nonhydrostatic thermodynamics and its geologic applications, Rev. Geophys. Space Phys., 11, 355-389, doi:10.1029/ RG011i002p00355.

Paterson, M. S. (2001), Relating experimental and geological rheology, Int. J. Earth Sci., 90, 157-167, doi:10.1007/s005310000158.

Paterson, M. S., and T. F. Wong (2005), Experimental Rock Deformation: The Brittle Field, 2nd ed., 335 pp., Springer, Berlin, Germany.

Pfiffner, O. A., and J. G. Ramsay (1982), Constraints on geological rate: Arguments from finite strain values of naturally deformed rocks, J. Geophys. Res., 87, 311-321, doi:10.1029/JB087iB01p00311.

Poirier, J. P. (1985), Creep of Crystals, 260 pp., Cambridge Univ. Press, Cambridge, U.K.

Raj, R. (1982), Creep in polycrystalline aggregates by matter transport through a liquid phase, J. Geophys. Res., 87, 4731-4739, doi:10.1029 JB087iB06p04731.

Ramsay, J. G., and M. I. Huber (1987), Folds and Fractures, vol. 2, 700 pp., Academic, London.

Regreny, A. (1973), Recristallisation hydrothermale du quartz, these doct. Ing. thesis, Univ. Paris IV, Paris.
Renard, F., P. Ortoleva, and J.-P. Gratier (1997), Pressure solution in sandstones: Influence of clays and dependence on temperature and stress, Tectonophysics, 280, 257-266, doi:10.1016/S0040-1951(97)00039-5.

Renard, F., J.-P. Gratier, and B. Jamtveit (2000), Kinetics of crack-sealing, intergranular pressure solution and compaction around active faults, J. Struct. Geol., 22, 1395-1407, doi:10.1016/S0191-8141(00)00064-X.

Renard, F., J. Schmittbuhl, J.-P. Gratier, P. Meakin, and E. Merino (2004), Three-dimensional roughness of stylolites in limestones, J. Geophys. Res., 109, B03209, doi:10.1029/2003JB002555.

Robin, P.Y (1978), Pressure solution at grain-to-grain contacts, Geochim Cosmochim. Acta, 42, 1383-1389, doi:10.1016/0016-7037(78)90043-1.

Rutter, E. H. (1976), The kinetics of rock deformation by pressure solution, Philos. Trans. R. Soc. London, 283, 203-219, doi:10.1098/ rsta.1976.0079

Rutter, E. H. (1983), Pressure solution in nature, theory and experiment, J. Geol. Soc., 140, 725-740, doi:10.1144/gsjgs.140.5.0725.

Schmittbuhl, T., F. Renard, J. P. Gratier, and R. Toussaint (2004), The roughness of stylolites implications of $3 \mathrm{D}$ high resolution topography measurements, Phys. Rev. Lett., 93, 238501, doi:10.1103/PhysRevLett.93.238501.

Schutjens, P. M. T. M. (1991), Experimental compaction of quartz sand at low effective stress and temperature conditions, J. Geol. Soc., 148, $527-$ 539, doi:10.1144/gsjgs.148.3.0527.

Shimizu, I. (1995), Kinetics of pressure solution creep in quartz: Theoretical considerations, Tectonophysics, 245, 121-134, doi:10.1016/00401951(94)00230-7.

Spiers, C. J., and P. M. T. M. Schutjens (1995), Densification of crystalline aggregates by fluid phase diffusional creep, in Deformation Processes in Minerals, Ceramics and Rocks, edited by D. J. Barber and P. G. Meredith, pp. 334-353, Unwin Hyman, Boston, Mass.

Spiers, C. J., S. De Meer, A. R. Niemeijer, and X. Zhang (2004), Kinetics of rock deformation by pressure solution and the role of thin aqueous films, in Physicochemistry of Water in Geological and Biological Systems. Structures and Properties of Thin Aqueous Films, Frontier Sci. Ser. vol. 44, edited by S. Nakashima et al., pp. 129-158, Univ. Acad. Press, Tokyo.

Tada, R., and R. Siever (1986), Experimental knife-edge pressure solution of halite, Geochim. Cosmochim. Acta, 50, 29-36, doi:10.1016/00167037(86)90045-1.

Tenthorey, E., and S. F. Cox (2006), Cohesive strengthening of fault zones during the interseismic period: An experimental study, J. Geophys. Res., 111, B09202, doi:10.1029/2005JB004122.

Urai, J. L., C. J. Spiers, H. J. Zwart, and G. S. Lister (1986), Weakening of rock-salt by water during long-term creep, Nature, 324, 554-557, doi: $10.1038 / 324554 \mathrm{a} 0$

Vidale, J., and Y.-G. Li (2003), Damage to the shallow Landers fault from the nearby Hector Mine earthquake, Nature, 421, 524-526, doi:10.1038/ nature 01354.

Weyl, P. K. (1959), Pressure solution and the force of crystallization: A phenomenological theory, J. Geophys. Res., 64, 2001-2025, doi:10.1029/JZ064i011p02001.

Wintsch, R. P., R. Christoffersen, and A. K. Kronenberg (1995), Fluid-rock reaction weakening of fault zones, J. Geophys. Res., 100, 13,02113,032, doi:10.1029/94JB02622.

Zhang, X., J. Salemans, C. J. Peach, and C. J. Spiers (2002), Compaction experiments on wet calcite powder at room temperature: Evidence for operation of intergranular pressure solution, in Deformation Mechanisms, Rheology and Tectonics: Current Status and Future Perspectives, edited by M. R. D. S. de Meer, J. H. P. de Bresser, and J. M. Pennock, Geol. Soc. Spec. Publ., 200, 29-40.

Zubtsov, S. F., F. Renard, J.-P. Gratier, R. Guiguet, D. K. Dysthe, and V. Traskine (2004), Experimental pressure solution creep of polymineralic aggregates, Tectonophysics, 385, 45-47, doi:10.1016/j.tecto. 2004.04.016.

D. Bernard, ICMCB, University of Bordeaux, CNRS, 87 avenue du Dr. Schweitzer, F-33608 Pessac, France.

J.-P. Gratier, R. Guiguet, and L. Jenatton, LGIT, Observatoire de Grenoble, University Joseph Fourier, CNRS, BP 53, F-38041 Grenoble, France. (jean-pierre.gratier@obs.ujf-grenoble.fr)

F. Renard, LGCA, Observatoire de Grenoble, University Joseph Fourier, BP 53, CNRS, F-38041 Grenoble, France. 